Engineering and Design

Elsevier Editorial System(tm) for Fusion

Manuscript Draft

Manuscript Number: FUSENGDES-D-15-00314R1

Title: Sweeping heat flux loads on divertor targets: thermal benefits and structural impacts

Article Type: Full Length Article

Keywords: DEMO, divertor, low cycle fatigue, high heat flux, plasmafacing component, strike-point sweeping

Corresponding Author: Dr. Jeong-Ha You, Dr.-Ing.

Corresponding Author's Institution: Max-Planck-Institute of Plasma Physics

First Author: Muyuan Li, Dr.-Ing.

Order of Authors: Muyuan Li, Dr.-Ing.; Francesco Maviglia; Gianfranco Federici; Jeong-Ha You, Dr.-Ing.

Abstract: One possibility to mitigate the maximum high heat flux (HHF) load on the target is to sweep the position of the strike-point back and forth periodically in order to spread the peak thermal load over a wider width. The aim of this work is to investigate the thermal and structuremechanical responses of a water-cooled tungsten mono-block target under cyclic HHF loads which are applied in sweeping modes. The study was performed by means of finite element analysis using an ITER-like target geometry. Extensive parametric simulations were carried out for a wide range of $\mathrm{HHF}$ loads and for selected sweeping amplitudes and frequencies, respectively. The simulation shows that the maximum temperature and the maximum heat flux to the coolant can be significantly reduced by sweeping. Sweeping offers advantages in terms of fatigue lifetime of interlayer as an emergency control action. Based on the fatigue lifetime prediction of interlayer, sweeping is suitable for the stationary loading if the sweeping frequency is high enough. 


\section{Cover letter}

In this contribution the thermal and structure-mechanical responses of a water-cooled tungsten mono-block target are investigated under cyclic heat flux loads which are applied in sweeping modes. An obvious benefit of the sweeping scheme in thermal performance is demonstrated while the impact on the fatigue lifetime is addressed. The quantitative results delivered in this contribution are very helpful to evaluation of the applicability of the sweeping concept. 
Reviewer \#1: I just would like to recommend that authors explain the calculation method of fatigue lifetime briefly in text.

Following text is added as suggested:

As in the LCF regime, the contribution from the plastic component is dominant, only the LCF part of the equation was considered in the present assessment of the LCF lifetime. The second term in Equation (2) is omitted. The equivalent plastic strain range was used instead of the total strain range and it is equal to the half of the cyclic increment of accumulated equivalent plastic strains, see Fig. 8. Thus, the LCF lifetime (number of cycles to failure) can be accessed using Equation (2).

Authors focused the plastic deformation of the copper interlayer and the hardening model applied for the cooper interlayer was mentioned in text. However, any hardening models on tungsten armor were not referenced in text. It should be mentioned because the plastic deformation of the tungsten could occur near the boundary between tungsten and copper interlayer under HHF and the plastic deformation of tungsten armor could also affect the total stress distribution of the mono-block. If any hardening models on tungsten were not considered, I would like to recommend checking the effect of the plastic deformation of tungsten armor for one or two cases of your analysis models.

Thanks for the comments. In this paper, the property of stress-relieved tungsten is assumed for the simulation, and no plastic deformation of tungsten near the interlayer shows in the simulation.

\section{Reviewer \#2:}

I think the paper you submitted is important and valuable contribution to the journal.

I have few minor comments only.

It would be good to add another figure, showing the temperature distribution in a typical case (also showing nodes 1-6) (Or perhaps incorporated in Fig.5 or 6-7 showing the relevant nodes?).

A figure (Fig.5) is added as suggested.

I think the definition of equivalent plastic strain is quite well known ans so equation (1) may not be necessary.

Equation (1) is deleted.

Could you please add a bit more explanation on the choice of parameter values? Why are 5 and $20 \mathrm{~cm}$ amplitudes are chosen? What drives it? Could it be less than $5 \mathrm{~cm}$ ? Or more than $20 \mathrm{~cm}$ ? What about in between, like 10 or $15 \mathrm{~cm}$ ? What about the frequency? Why 0.5 and $1 \mathrm{~Hz}$ ? And why $4 \mathrm{~Hz}$ in the end? It is clear that very high frequencies would limit the fatigue life time and very low ones increase the temperature peak, but what would be the sensible limits or how could they be found? 
The sweeping frequency and amplitudes where preliminary scanned in a broader operational space with amplitude 3 to $40 \mathrm{~cm}$ peak to peak and frequencies from 0.1 to $5 \mathrm{~Hz}$. The lower limitation in amplitude was given by the estimation of the DEMO footprint on the target, which, at $20 \mathrm{MW} / \mathrm{m}^{\wedge} 2$ is about $10 \mathrm{~cm}$ for the region with a heat-flux above $1 \mathrm{MW} / \mathrm{m}^{\wedge} 2$, making the $3 \mathrm{~cm}$ a reasonable minimum movement. Below $5 \mathrm{~cm}$ the effect on the beneficial effects on heat flux and temperature decreasing proved to be much reduced. The $40 \mathrm{~cm}$ amplitude is instead a limit due to the maximum target length, which in ITER if around $1.5 \mathrm{~m}$ and the need to account for possible strike movements coming from plasma VDE or other disturbances. The subset of 5 to $20 \mathrm{~cm}$ was finally chosen as a compromise of the above reasons and also to limit the current which would be needed to achieve the movement of up to $20 \mathrm{~cm}$ with around $240 \mathrm{Mat}$, which is a value in line with the ITER in vessel coils used for the vertical stabilization.

For what concern the frequency chosen, which is directly dependent on the thermal time constant of the monoblock, it was noted that above 1Hz the effect on the heat flux to the coolant was almost saturated, and the maximum temperatures on the tungsten surface and copper interlayer where brought below, respectively, the recrystallization (1200C) and softening/aging point (350C). Another driving point was the power needed to drive the sweeping at these frequencies which is of Active pow. $0.30 \mathrm{MW}$ at $0.2 \mathrm{~Hz}, 3.3 \mathrm{MW}$ at $1 \mathrm{~Hz}$, Reactive pow. 3.5MVAr e $0.2 \mathrm{~Hz}, 16 \mathrm{MVAr}$ e $1 \mathrm{~Hz}$.

Finally it was found out during the thermal fatigue analysis that the deltaT in the copper interlayer obtained at $1 \mathrm{~Hz}$ would lead to a short lifetime of the component, and would make the sweeping suitable only as an emergency maneuver. For this reason it was decided to run a further case at $4 \mathrm{~Hz}$. At this frequency the lifetime of the copper interlayer is compatible with continuous sweeping operation during the flattop.

Revised texts are marked with yellow color. The authors like to thank to both reviewers very much again for their helpful comments and correction. 


\section{Highlights}

- Parametric simulations were performed to study the impact of strike-point sweeping.

- Temperature and heat flux to the coolant can be significantly reduced by sweeping.

- Higher sweeping frequency $(0.5-4 \mathrm{~Hz})$ offers advantages for fatigue lifetime.

- Sweeping is suitable for stationary loading if frequency is high enough (e.g. $4 \mathrm{~Hz}$ ). 


\title{
Sweeping heat flux loads on divertor targets: thermal benefits and structural impacts
}

\author{
Muyuan $\mathrm{Li}^{\mathrm{a}}$, Francesco Maviglia ${ }^{\mathrm{b}}$, Gianfranco Federici ${ }^{\mathrm{b}}$, Jeong-Ha You ${ }^{\mathrm{a}, *}$ \\ ${ }^{a}$ Max-Planck-Institut für Plasmaphysik, Boltzmannstr.2, 85748 Garching, Germany \\ ${ }^{b}$ EUROfusion Consortium, PPPT Department, Boltzmannstr.2, 85748 Garching, Germany
}

\section{Highlights}

- Parametric simulations were performed to study the impact of strike-point sweeping.

- Temperature and heat flux to the coolant can be significantly reduced by sweeping.

- Higher sweeping frequency $(0.5-4 \mathrm{~Hz})$ offers advantages for fatigue lifetime.

- Sweeping is suitable for stationary loading if frequency is high enough (e.g. $4 \mathrm{~Hz}$ ).

\begin{abstract}
One possibility to mitigate the maximum high heat flux (HHF) load on the target is to sweep the position of the strike-point back and forth periodically in order to spread the peak thermal load over a wider width. The aim of this work is to investigate the thermal and structure-mechanical responses of a water-cooled tungsten mono-block target under cyclic HHF loads which are applied in sweeping modes. The study was performed by means of finite element analysis using an ITER-like target geometry. Extensive parametric simulations were carried out for a wide range of HHF loads and for selected sweeping amplitudes and frequencies, respectively. The simulation shows that the maximum temperature and the maximum heat flux to the coolant can be significantly reduced by sweeping. For the parameters studied in this work $(0.5-4 \mathrm{~Hz}, 5-20 \mathrm{~cm})$, higher sweeping frequency or smaller sweeping amplitude offers advantages in terms of fatigue lifetime of interlayer. Sweeping is suitable for the stationary loading if the sweeping frequency is high enough (e.g. $4 \mathrm{~Hz}$ ) based on the fatigue lifetime prediction of interlayer.
\end{abstract}

\footnotetext{
*Corresponding author. Tel.: +49 (0)893299 1373; fax:+49 (0)893299 1212.

Email address: you@ipp.mpg.de (Jeong-Ha You)
} 
keyword: DEMO, divertor, low cycle fatigue, high heat flux, plasma-facing component, strike-point sweeping

\section{Introduction}

In a tokamak-type fusion reactor, the plasma particles being detracted from the scrap-off layer onto the divertor target produce high heat flux (HHF) loads on the surface of the plasma facing target. The thermal loads are distributed highly heterogeneously over the poloidal positions of the target and locally concentrated around the strike-point which is the narrow intersection band of the separatrix with the target.

In the case of ITER divertor, the peak heat flux at the strike-point is predicted to reach $10 \mathrm{MW} / \mathrm{m}^{2}$ during stationary normal operation and even up to $20 \mathrm{MW} / \mathrm{m}^{2}$ during slow transient events which could last at least for a couple of seconds [1, 2]. For exhaustion of the thermal power, a water-cooled tungsten monoblock target equipped with copper alloy tubes was employed for the ITER divertor. The recent HHF qualification tests conducted on the prototypes of ITER divertor target revealed that substantial damages were produced in the tungsten armor (deep cracks, melting) and in the cooling tube (plastic deformation), when the applied heat flux load approached $20 \mathrm{MW} / \mathrm{m}^{2}[\underline{3}, 4]$. This result raises a critical concern in terms of the structural integrity and reliability of the target components under high transient thermal loads.

In the case of DEMO divertor target, the currently assumed HHF loads lie in the comparable range with those of the ITER divertor target. Therefore, the damage features mentioned above in relation to the ITER divertor target would still indicate critical design issues for the DEMO divertor target as well. Furthermore, the fracture failure risk of the armor, and potentially the tube as well, will become increasingly serious for the DEMO divertor target, as the neutron irradiation dose is expected to be at least an order of magnitude higher (3-6 dpa/fpy for the tungsten armor) than that of the ITER divertor target [5]. However, the technical feasibility to avoid or to mitigate the critical failure features seems to be quite limited. From the viewpoint of the current technological readiness, the metallurgical enhancement of the toughness of tungsten or copper alloy has been obviously stagnating. On the other hand, the safety margin of the target concept may not be sufficient in terms of structural design criteria, when the HHF load is increased toward $20 \mathrm{MW} / \mathrm{m}^{2}$. This trend is valid for the tungsten armor as well, although the armor is usually not regarded as actual structural part according to the conventional classification. Given such a highly demanding environment of structuremechanical loading that is nearly approaching the performance limit, there arises a need to reduce and keep under control the peak thermal load down to a safe level.

One of the potential (maybe more fundamental) solutions would be to control in real time the radiative 
loss of fusion power( in DEMO in excess of 90\%) while maintaining the divertor plasma in a detached regime constantly. However, the required technologies are by far distant from the engineering maturity. Even the underlying physics is only partly understood up to now that it will surely be only a long-term mission. How robust and reliable this control technique will be able to be is another concern besides its basic feasibility. A possible failure of any controlling sequence is likely to cause a sudden increase of heat flux up to $20 \mathrm{MW} / \mathrm{m}^{2}$, where irreversible damage may be produced. When the loss-of-detachment event is continually repeated due to the misfunction of the control system, the accumulated damage may eventually result in the global failure of a whole component within an unacceptably short operation lifetime.

Another possibility to mitigate the maximum HHF load on the target is to sweep the position of the strike-point back and forth periodically in order to spread the peak thermal load over a wider width. The concept of strike-point sweeping has already been successfully implemented into the JET experiment campaigns [6, 7, 8]. It was applied to the divertor design of the superconducting W7-X as well [9, 10]. A number of aspects need to be considered for evaluating the applicability of the sweeping concept [11]. For DEMO this technique could be applied either as an emergency control action, in case a sudden increase of the thermal load on the divertor target is detected, or as a steady state control scheme during normal operation. Extensive numerical estimations are being carried out to study the impact of various parameters on the thermal response of a target under sweeping operation, for instance, dimension of armor and heat sink, coolant inlet temperature, materials properties, and the time to coolant burn out. Additionally, to explore the feasibility of the sweeping technique for normal operation, comprehensive analyses are needed including required power, optimal amplitude and frequency of sweeping, impact on plasma shape and confinement quality, power dissipation due to the alternating currents induced in the neighboring superconductor coils and local temperature increase, and thermal fatigue of the materials due to the cyclic variation of thermal stresses. Among the above mentioned aspects, the impact of the sweeping is studied based on thermal and structure-mechanical responses in this work.

The aim of this work is to investigate the thermal and structure-mechanical responses of a water-cooled tungsten mono-block target under cyclic heat flux loads which are applied in sweeping modes. The focus is on the quantitative assessment of thermal benefits, namely, the reduction of peak temperature and maximum heat flux to the heat sink, and of structural risk caused by the thermal fatigue of the heat sink. The study was performed by means of finite element analysis using an ITER-like target geometry. Extensive parametric simulations were carried out for a wide range of HHF loads and for two selected sweeping amplitudes and frequencies, respectively. An obvious benefit of the sweeping scheme in thermal performance is demonstrated while the impact on the fatigue lifetime is addressed. 


\section{FE model}

\subsection{Geometry, FE mesh and materials}

Fig. 1] shows the assumed footprint of the heat flux power on the outer target according to the latest prediction for DEMO based on [12]. The target consists of a number of small rectangular tungsten block connecting by a cooling tube. Two neighboring blocks are separated by a thin gap ( $\sim 0.3 \mathrm{~mm})$. To study the influence of periodic strike point oscillation, the footprint of the heat flux power is swept at the surface of the targets along the axis direction of the cooling tube ( $x$-axis), see Fig. 2. The heat flux profile along the $y$-axis is assumed to be constant. The control point of the sweeping is set to be the 0 width position in Fig. 1. The sweeping amplitude is defined as the distance between the rightmost and leftmost positions of the control point during sweeping. One mono-block divertor is selected for the thermal analysis in this work, and the rightmost position of the control point lies on the right edge of the top surface of the selected monoblock divertor. The position where the maximum temperature occurs during sweeping is dependent on the sweeping amplitude and the sweeping frequency. According to a rough estimation from a $2 \mathrm{D}$ finite element (FE) simulation, the difference between the maximum temperatures of the targets and of the selected monoblock divertor is less than $100^{\circ} \mathrm{C}$ for loading conditions studied in this work. For simplicity, the selected mono-block divertor is used for all the loading combinations.

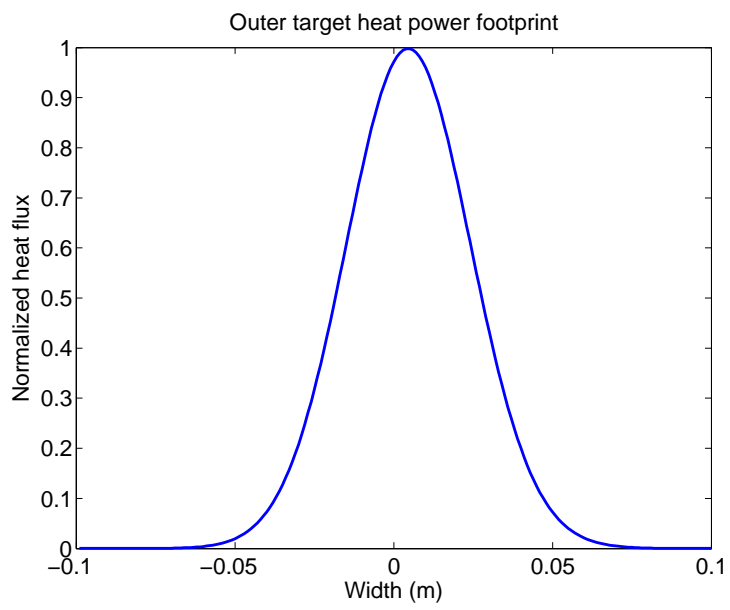

Fig. 1. The assumed footprint of the heat flux power on the outer target is according to the latest prediction for DEMO based on [12].

The PFC model considered for the FEM study is a water-cooled tungsten mono-block duplex structure consisting of a tungsten armor block and a copper alloy cooling tube (heat sink). The geometry, the FE mesh and the constituent materials of the considered model PFC are shown in Fig. 3, The tungsten armor block has dimensions of $23 \times 22 \times 4 \mathrm{~mm}$. The cooling tube has a thickness of $1.0 \mathrm{~mm}$ and an inner diameter 


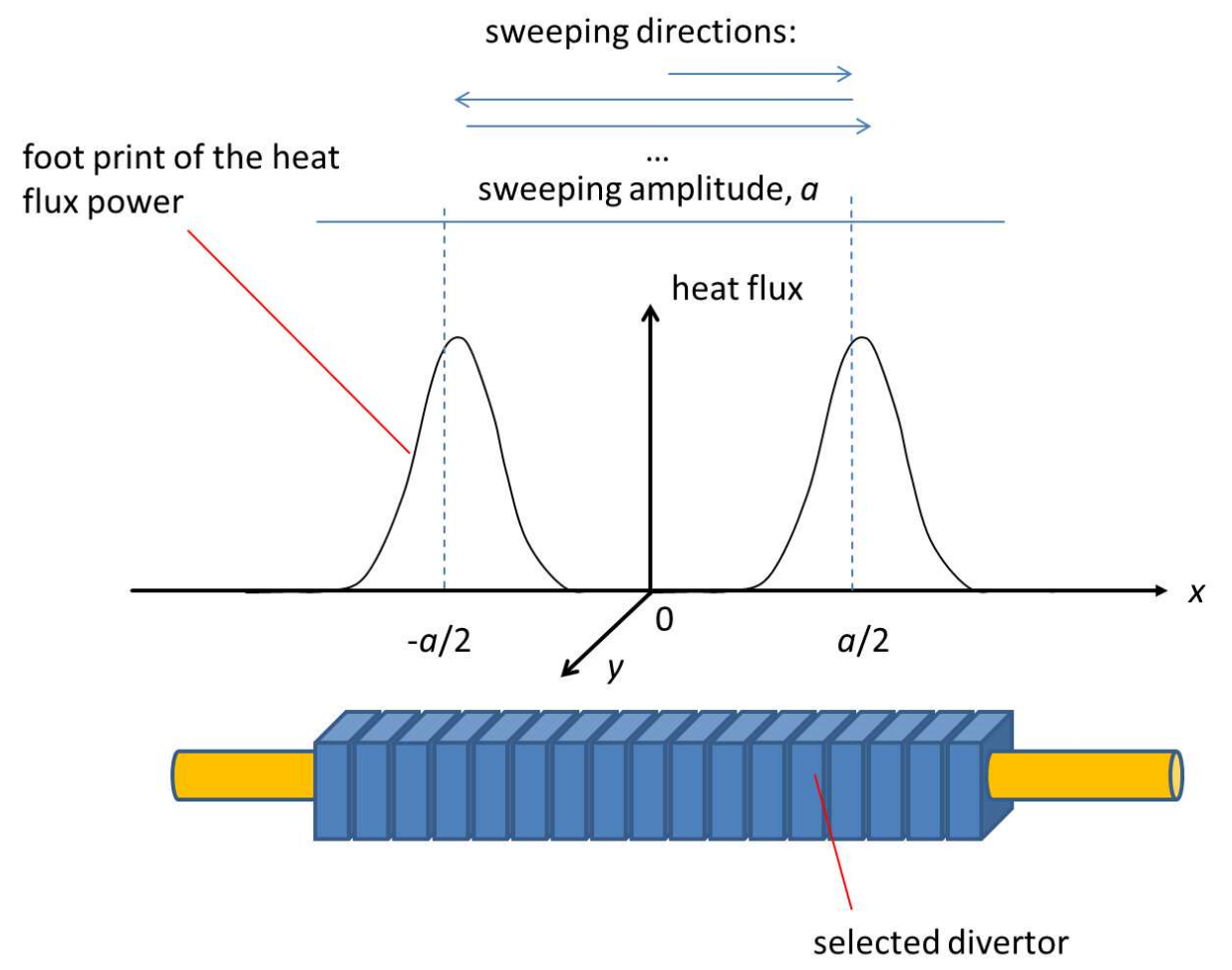

Fig. 2. Schematic drawing of sweeping the footprint of the heat flux power.

of $12 \mathrm{~mm}$. The thickness of the copper interlayer is $0.5 \mathrm{~mm}$. The geometry used here is based on the optimization of the geometry of the ITER tungsten divertor [13]. The commercial FEM code ABAQUS was employed for the numerical studies using quadratic brick elements of 20 nodes each. In total, there were 8496 finite elements. The mesh in the critical region of the component was refined.

At the selected mono-block divertor, the maximum temperature occurs at the left edge during sweeping. The nodes 1,2 and 3 at the left edge are therefore selected to characterize the maximum temperatures in tungsten block, between tungsten and copper, and between copper alloy and coolant water for sweeping cases. The simulation for a stationary case is also performed as a reference. In the stationary case, the heat flux peak is positioned at the middle line between the left and right edges of the top surface. The nodes 4 , 5 and 6 are used to characterize the maximum temperatures for the stationary case.

The thermo-mechanical simulations are based on data of several materials in the PFC model. Cross-rolled and stress-relieved tungsten was applied for the tungsten armor block. A precipitation-hardened copper alloy $(\mathrm{CuCrZr})$ was considered for the heat sink tube and soft-annealed copper constituted the interlayer. The Frederick-Armstrong constitutive model applied for copper and the copper alloy is based on the combination of non-linear isotropic and kinematic hardening laws [14, 15, 16]. Temperature-dependent material properties 


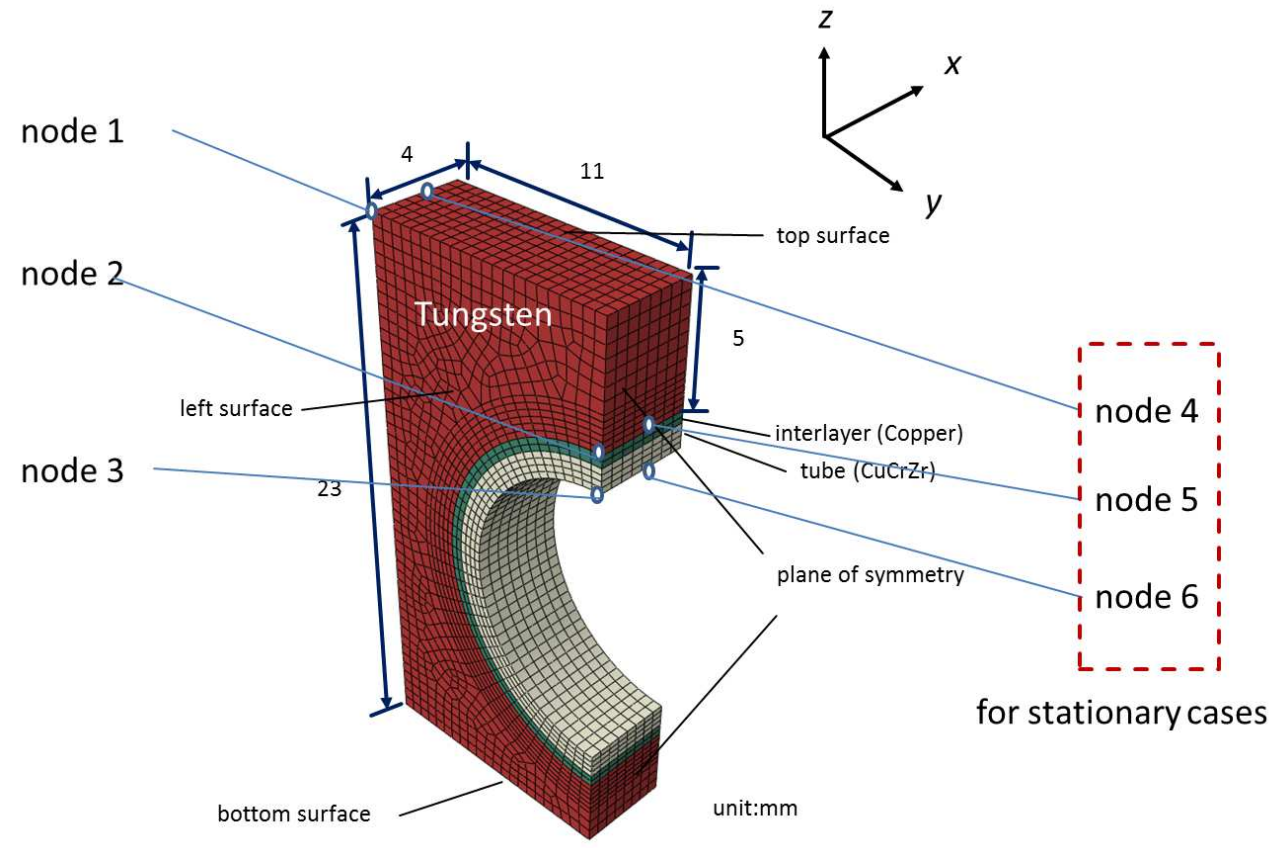

Fig. 3. The FE mesh of the mono-block divertor model. Due to symmetry only one half of the structure was considered.

are listed in Table 1at selected temperatures, corresponding to the operation temperatures for the considered materials. It should be noted that the materials are assumed to be unirradiated due to lack of data of irradiated materials.

\subsection{Loads and boundary conditions}

The peak heat flux densities of $15 \mathrm{MW} / \mathrm{m}^{2}, 20 \mathrm{MW} / \mathrm{m}^{2}$ and $30 \mathrm{MW} / \mathrm{m}^{2}$ are applied in this study. Before the HHF load is applied, the PFC is assumed to have a uniform temperature (coolant temperature) without any residual stress. For a parametric study, the sweeping amplitudes of $5 \mathrm{~cm}$ and $20 \mathrm{~cm}$ are chosen. The sweeping frequency varies from $1 \mathrm{~Hz}$ to $0.5 \mathrm{~Hz}$. Two further simulations that consider $10 \mathrm{MW} / \mathrm{m}^{2}$ and $4 \mathrm{~Hz}$ are also performed to study the vadilty of applying sweeping as a steady state control scheme during normal operation.

The heat transfer coefficient (HTC) between the inner wall of the heat sink tube and the coolant water is plotted in Fig. 4. It is calculated using SIEDER/TATE [19] and CEA/THOM [20] correlations for forced convection and subcooled boiling regimes, respectively. The pressure of the coolant water is $5 \mathrm{MPa}$. The coolant water velocity is $12 \mathrm{~m} / \mathrm{s}$. The temperature of the coolant water is $200^{\circ} \mathrm{C}$. A swirl tape (thickness: $0.8 \mathrm{~mm}$, twist ratio: 2) in the tube was assumed in the calculation of heat transfer coefficient. 
Table 1. Properties of the considered materials at selected temperatures [17, 18].

\begin{tabular}{|c|c|c|c|c|c|c|c|}
\hline & \multicolumn{3}{|c|}{ Tungsten $^{1}$} & \multicolumn{2}{|c|}{$\mathrm{CuCrZr}^{2}$} & \multicolumn{2}{|c|}{ Copper $^{3}$} \\
\hline & $20^{\circ} \mathrm{C}$ & $400^{\circ} \mathrm{C}$ & $1200^{\circ} \mathrm{C}$ & $20^{\circ} \mathrm{C}$ & $400^{\circ} \mathrm{C}$ & $20^{\circ} \mathrm{C}$ & $400^{\circ} \mathrm{C}$ \\
\hline Young's modulus (GPa) & 398 & 393 & 356 & 115 & 106 & 115 & 95 \\
\hline Yield stress (MPa) & 1385 & 1100 & 346 & 273 & 238 & 3 & 3 \\
\hline$Q^{*}(\mathrm{MPa})$ & & & & -43 & -68 & 76 & 36 \\
\hline$b^{*}$ & & & & 6 & 10 & 8 & 25 \\
\hline$C^{*}(\mathrm{MPa})$ & & & & 148575 & 117500 & 64257 & 31461 \\
\hline$\gamma^{*}$ & & & & 930 & 1023 & 888 & 952 \\
\hline Heat conductivity $(\mathrm{W} / \mathrm{mK})$ & 175 & 140 & 105 & 318 & 347 & 379 & 352 \\
\hline $\begin{array}{l}\text { Coefficient of } \\
\text { thermal expansion }\left(10^{-6} / \mathrm{K}\right)\end{array}$ & 4.5 & 4.6 & 5.3 & 16.7 & 17.8 & 17.8 & 18.1 \\
\hline
\end{tabular}

${ }_{1}$ Rolled and stress-relieved state.

2 Precipitation-hardened state, the reference alloy: Elmedur-X (code: $\mathrm{CuCr} 1 \mathrm{Zr}, \mathrm{Cr}: 0.8 \%, \mathrm{Zr}: 0.08 \%$ ).

${ }^{3}$ Softened by annealing at $700^{\circ} \mathrm{C}$ for $1 \mathrm{~h}$.

* Material parameters entering the Frederick-Armstrong constitutive model [18].

At two ends of the cooling tube, a planar axial displacement constraint is given. 


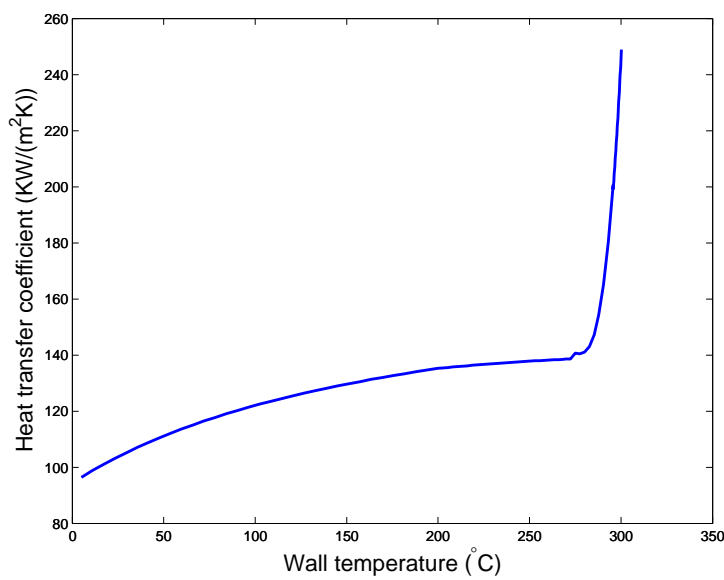

Fig. 4. Heat transfer coefficient between the inner wall of the heat sink tube and the coolant water. The coolant water velocity is $12 \mathrm{~m} / \mathrm{s}$. Pressure of the coolant water is $5 \mathrm{MPa}$. The temperature of the coolant water is $200^{\circ} \mathrm{C}$. A swirl tape (thickness: $0.8 \mathrm{~mm}$, twist ratio: 2) in the tube was assumed.

\section{Results and discussion}

\subsection{Critical heat flux}

The simulations were conducted with different sweeping frequencies and sweeping amplitudes. A higher sweeping frequency leads more thermal cycles within the same time but less loading time for each thermal cycle. Increasing the sweeping amplitude results in spreading the energy in a larger area, i.e. the energy input is reduced for each mono-block. Table 2 lists the heat flux densities at copper alloy-water interface (at node 3). The critical heat flux density is $25.3 \mathrm{MW} / \mathrm{m}^{2}$ at wall temperature of $300^{\circ} \mathrm{C}$ for a coolant temperature of $200^{\circ} \mathrm{C}$ calculated using modified Tong 75 correlation according to the CEA formulation. When the heat flux to the coolant is above the critical value, the coolant loses heat removal capability. This effect is not included in the simulations. In the simulation, if the wall temperature is higher than $300^{\circ} \mathrm{C}$, the

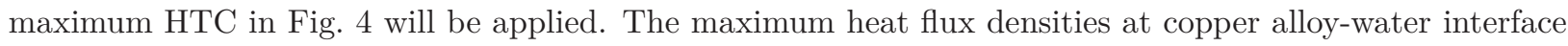
of stationary cases for $20 \mathrm{MW} / \mathrm{m}^{2}$ and $30 \mathrm{MW} / \mathrm{m}^{2}$ as well as sweeping cases with a sweeping amplitude of $5 \mathrm{~cm}$ for $30 \mathrm{MW} / \mathrm{m}^{2}$ are much larger than the critical heat flux and not listed here. Those results are not unrealistic due to the fact that the HTC above the CHF is not correctly implemented in the simulations. In general, this work focuses on the cases in which the maximum heat flux to the coolant is below the CHF. For the stationary case of $15 \mathrm{MW} / \mathrm{m}^{2}$, the maximum heat flux density $\left(25.4 \mathrm{MW} / \mathrm{m}^{2}\right)$ is slightly above the critical value $\left(25.3 \mathrm{MW} / \mathrm{m}^{2}\right)$, but considering that this only occurs in a limited area of the wall surface, the result is acceptable as a reference. 
When a sweeping amplitude of $20 \mathrm{~cm}$ is applied, the maximum heat flux density to the coolant can be reduced below the critical value. For the best combination of sweeping amplitude and frequency (20 cm and $1 \mathrm{~Hz}$ ) listed in Table 2, the maximum heat flux density to the coolant can be reduced by a factor of 4. Furthermore, as the loading time on one mono-block divertor is significantly reduced by sweeping, the damage induced by a sudden increase of the heat flux density will be smaller than that in the stationary cases.

Table 2. Maximum heat flux density $\left(\mathrm{MW} / \mathrm{m}^{2}\right)$ temperature $\left.\left({ }^{\circ} \mathrm{C}\right)\right]$ at copper alloy-water interface (at node 3$)$.

\begin{tabular}{|c|c|c|c|c|c|c|}
\hline Peak heat flux density $\left(\mathrm{MW} / \mathrm{m}^{2}\right)$ & \multicolumn{2}{|c|}{15} & \multicolumn{2}{|c|}{20} & \multicolumn{2}{|c|}{30} \\
\hline Sweeping frequency $(\mathrm{Hz})$ & 0.5 & 1 & 0.5 & 1 & 0.5 & 1 \\
\hline Sweeping amplitude (cm) & & & & & & \\
\hline 5 & $20.6(297)$ & $18.2(295)$ & - & $24.8(300)$ & - & - \\
\hline 20 & $8.6(262)$ & $6.0(243)$ & $11.3(280)$ & $7.8(257)$ & $19.0(295)$ & $11.6(281)$ \\
\hline Stationary case & \multicolumn{2}{|c|}{$25.4(302)$} & \multicolumn{2}{|l|}{-} & \multicolumn{2}{|c|}{ - } \\
\hline
\end{tabular}

\subsection{Temperature}

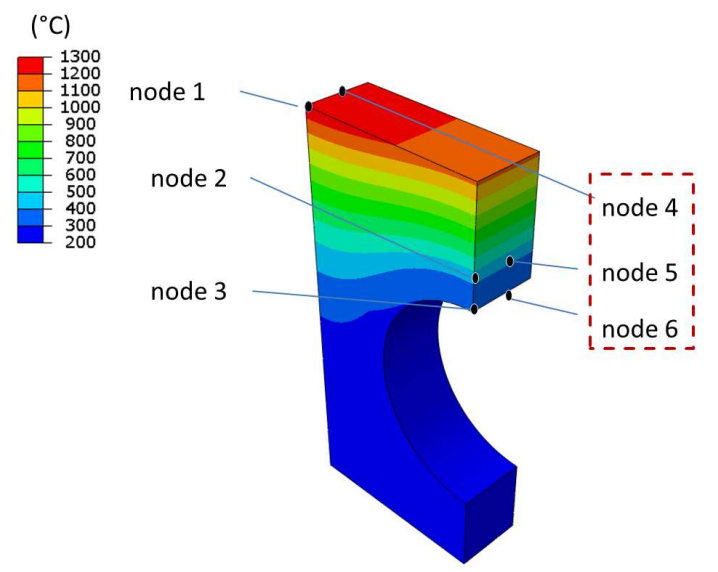

Fig. 5. Temperature distribution for a stationary heat flux of $15 \mathrm{MW} / \mathrm{m}^{2}$. The locations of the reference nodes are also illustrated.

In Fig. 5. a typical temperature distribution of the divertor under HHF load is shown, where the locations of the reference nodes are also illustrated. Fig. 6] shows temperature and heat flux density at node 1 as a function of time for a peak heat flux density of $15 \mathrm{MW} / \mathrm{m}^{2}$ with a sweeping frequency of $1 \mathrm{~Hz}$ and a sweeping amplitude of $5 \mathrm{~cm}$. Two peaks of heat flux density at node 1 in one thermal cycle are quite close to each other, since the selected mono-block is located near the edge of the sweeping area. The peak temperature occurs shortly after the occurrence of the second peak of the heat flux density. After a few seconds, a 


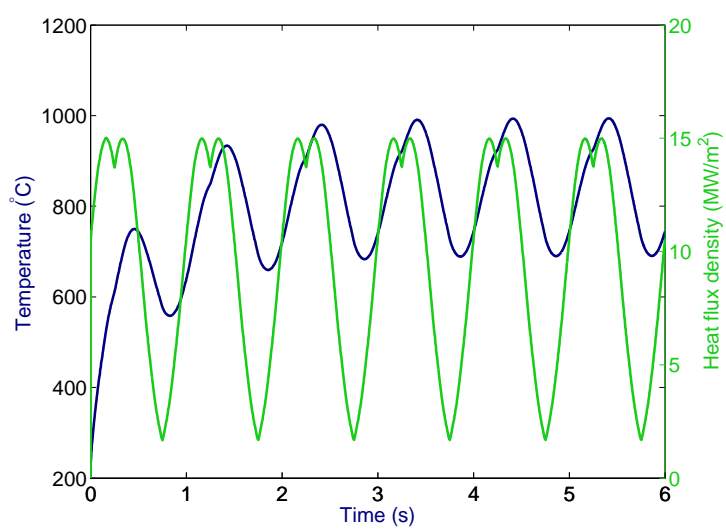

Fig. 6. Temperature and heat flux density at node 1 as a function of time for a peak heat flux density of $15 \mathrm{MW} / \mathrm{m}^{2}$ with sweeping frequency of $1 \mathrm{~Hz}$ and sweeping amplitude of $5 \mathrm{~cm}$.

saturated thermal cycle is observed.

Table 3. Maximum / Minimum (amplitude) temperatures $\left({ }^{\circ} \mathrm{C}\right)$ at node 1 in the saturated thermal cycle.

\begin{tabular}{|c|c|c|c|c|}
\hline Sweeping amplitude $(\mathrm{cm})$ & \multicolumn{2}{|c|}{5} & \multicolumn{2}{|c|}{20} \\
\hline Sweeping frequency $(\mathrm{Hz})$ & 0.5 & 1 & 0.5 & 1 \\
\hline Peak heat flux density $\left(\mathrm{MW} / \mathrm{m}^{2}\right)$ & & & & \\
\hline & $1076 / 606(470)$ & $993 / 698(295)$ & $645 / 244(401)$ & $551 / 271(280)$ \\
\hline Maximum temperature (stationary) & & & & \\
\hline 20 & - & $1281 / 896(385)$ & $800 / 247(553)$ & $671 / 294(377)$ \\
\hline $\begin{array}{l}\text { Maximum temperature (stationary) } \\
30 \\
\text { Maximum temperature (stationary) }\end{array}$ & - & $x^{\prime}$ & $1119 / 286(833)$ & $920 / 342(578)$ \\
\hline
\end{tabular}

- critical heat flux is reached.

Fig. 7 shows the temperature at node 1 for peak heat flux densities of $15 \mathrm{MW} / \mathrm{m}^{2}, 20 \mathrm{MW} / \mathrm{m}^{2}$ and $30 \mathrm{MW} / \mathrm{m}^{2}$. The temperature is much higher for a sweeping amplitude of $5 \mathrm{~cm}$ than $20 \mathrm{~cm}$. When the sweeping frequency increases, the peak temperature decreases. As a result, the peak temperature at the top surface of the mono-block can be reduced by increasing either the sweeping amplitude or the sweeping frequency. However, increasing the sweeping amplitude will be limited by the geometry of divertor target. A higher sweeping frequency will require more thermal cycles during the operation, but at the same time, it reduces the temperature variation as well as the loading time in each thermal cycle. The former will certainly shorten the actual operating time but the later will enlarge the allowed number of load cycles (fatigue lifetime). The study of impact of increasing sweeping frequency on LCF behavior will be shown later in this section.

Table 3 gives maximum and minimum temperatures at node 1 in the saturated thermal cycle. When 


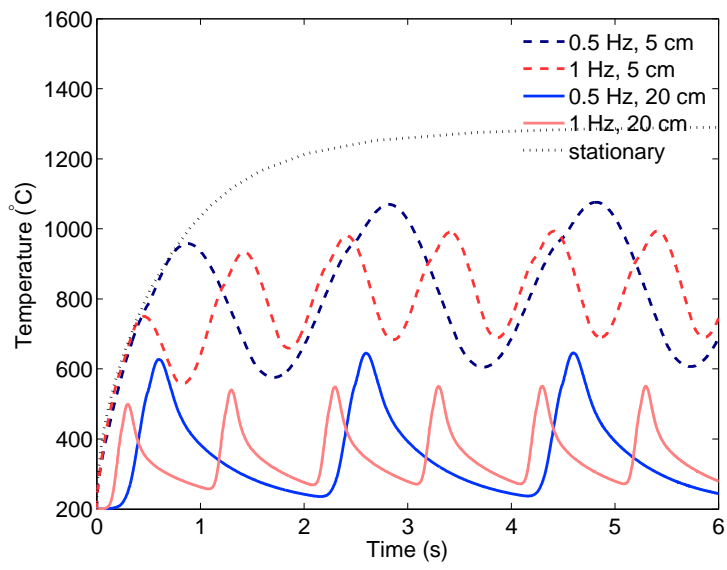

(a) Peak heat flux density: $15 \mathrm{MW} / \mathrm{m}^{2}$

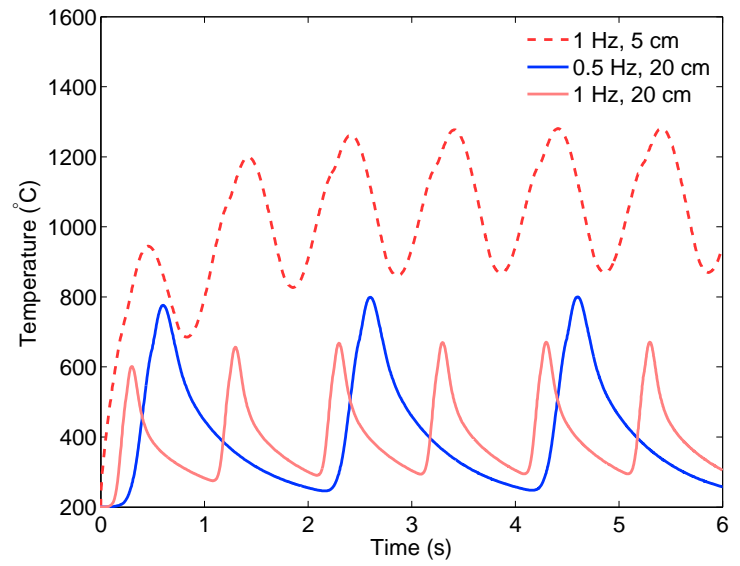

(b) Peak heat flux density: $20 \mathrm{MW} / \mathrm{m}^{2}$

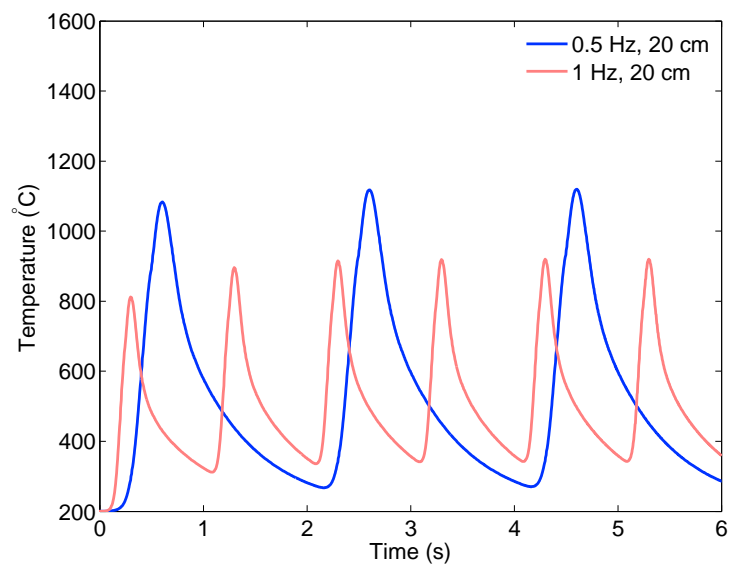

(c) Peak heat flux density: $30 \mathrm{MW} / \mathrm{m}^{2}$

Fig. 7. Temperature at node 1 as a function of time for different peak heat flux densities.

the sweeping frequency increases from 0.5 to $1 \mathrm{~Hz}$, the maximum temperature decreases and the minimum temperature increases. As a result, the temperature amplitudes drop more than $30 \%$. When the sweeping amplitude of $20 \mathrm{~cm}$ is applied instead of $5 \mathrm{~cm}$, both the maximum and the minimum temperatures decrease, and the reduction in the temperature variation amplitude is less than $15 \%$, which deceases with increasing the frequency. For the peak heat flux density of $20 \mathrm{MW} / \mathrm{m}^{2}(1 \mathrm{~Hz}$ and $5 \mathrm{~cm})$ and $30 \mathrm{MW} / \mathrm{m}^{2}(0.5 \mathrm{~Hz}$ and $20 \mathrm{~cm})$, the maximum temperatures enter the crystallization temperature range of tungsten $\left(1100-1400^{\circ} \mathrm{C}\right)$. When tungsten at the surface layer is recrystallized, the strength of tungsten is significantly reduced, and major cracks have been observed in the heat flux tests of divertors [3]. When there is no recrystallized layer at the surface, the brittle cracking is not critical in the tungsten armor block [21].

Fig. 8 shows the temperature at node 2 for peak heat flux densities of $15 \mathrm{MW} / \mathrm{m}^{2}, 20 \mathrm{MW} / \mathrm{m}^{2}$ and $30 \mathrm{MW} / \mathrm{m}^{2}$. The impact of the sweeping amplitude and the sweeping frequency on the temperature is 


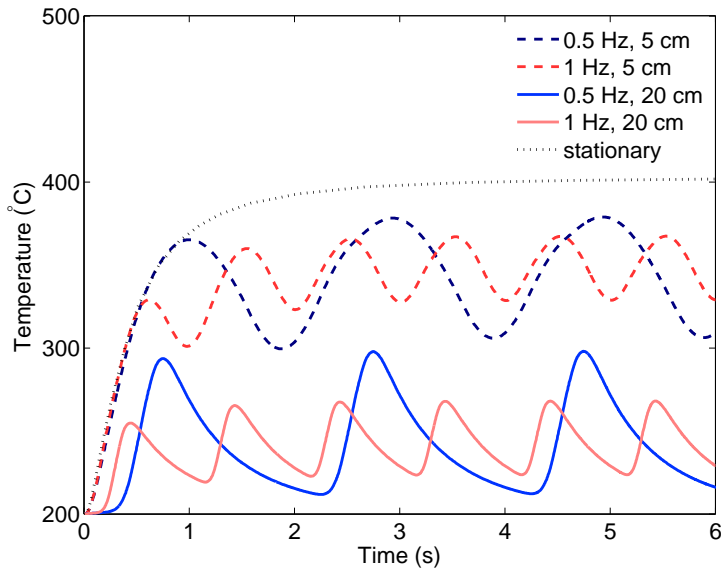

(a) Peak heat flux density: $15 \mathrm{MW} / \mathrm{m}^{2}$

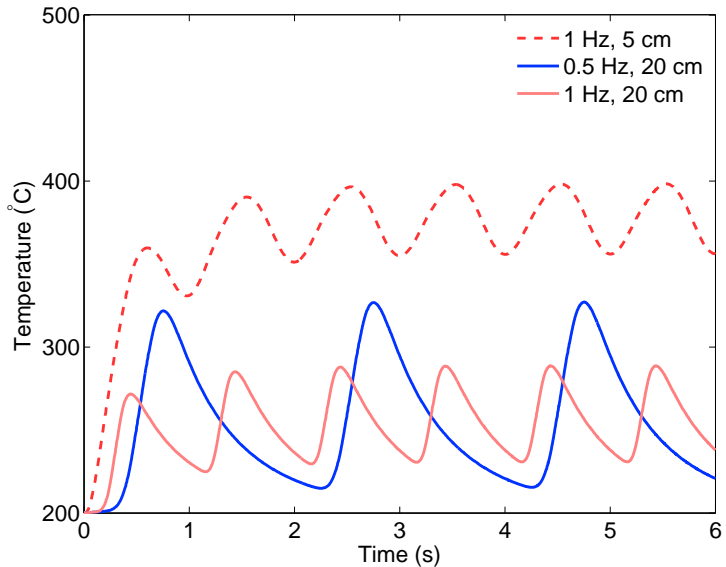

(b) Peak heat flux density: $20 \mathrm{MW} / \mathrm{m}^{2}$

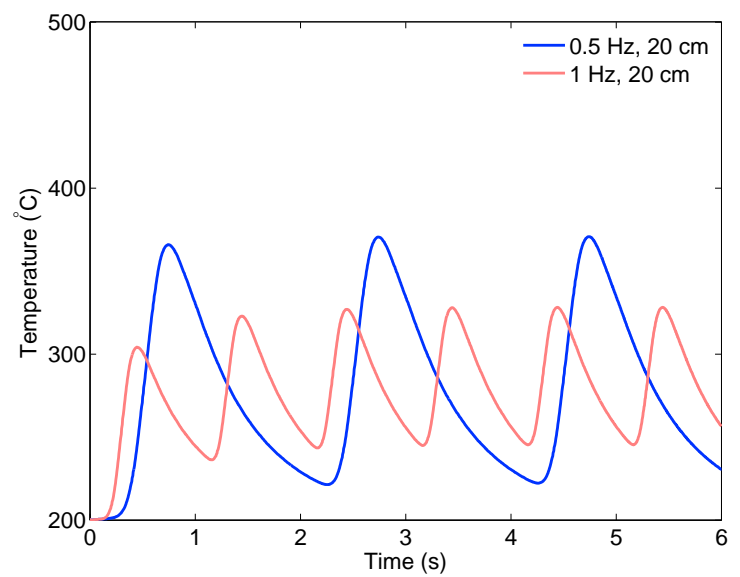

(c) Peak heat flux density: $30 \mathrm{MW} / \mathrm{m}^{2}$

Fig. 8. Temperature at node 2 as a function of time.

similar. The maximum temperature in the saturated thermal cycle can be reduced below $400^{\circ} \mathrm{C}$ by applying a sweeping amplitude of $20 \mathrm{~cm}$ for the peak heat flux density of up to $30 \mathrm{MW} / \mathrm{m}^{2}$. The high temperature (above $400^{\circ} \mathrm{C}$ ) is critical at the interface between tungsten armor block and copper interlayer, as the copper will become softer. Maximum and minimum temperatures at node 2 are listed in Table 4 . Compared to the situation at the top surface, the temperature variation at node 2 is less significant and its amplitude is less than $20 \%$ of that at node 1 . However, the temperature variation in the copper interlayer is more critical, since a large amount of plastic deformation will be generated due to the temperature variation leading to LCF failure 22]. Different from the trend of maximum temperatures at the top surface, the temperature amplitude increases, if the sweeping amplitude increase from $5 \mathrm{~cm}$ to $20 \mathrm{~cm}$. This is because for the sweeping amplitude of $20 \mathrm{~cm}$, the selected mono-block can be cooled to a lower temperature. 
Table 4. Maximum / Minimum (amplitude) temperatures $\left({ }^{\circ} \mathrm{C}\right)$ at node 2 in the saturated thermal cycle.

\begin{tabular}{|c|c|c|c|c|}
\hline Sweeping amplitude $(\mathrm{cm})$ & \multicolumn{2}{|c|}{5} & \multicolumn{2}{|c|}{20} \\
\hline Sweeping frequency $(\mathrm{Hz})$ & 0.5 & 1 & 0.5 & 1 \\
\hline $\begin{array}{l}\text { Peak heat flux density }\left(\mathrm{MW} / \mathrm{m}^{2}\right) \\
15\end{array}$ & $378 / 306(72)$ & $367 / 328(39)$ & $297 / 216(81)$ & $268 / 223(45)$ \\
\hline Maximum temperature (stationary) & & & & \\
\hline 20 & - & $398 / 355(43)$ & $327 / 215(112)$ & $288 / 230(58)$ \\
\hline Maximum temperature (stationary) & & & & \\
\hline 30 & - & - & $370 / 230(140)$ & $328 / 245(83)$ \\
\hline Maximum temperature (stationary) & & & & \\
\hline
\end{tabular}

\subsection{Fatigue lifetime}

In the literature, most of the LCF data are obtained from a uniaxial cyclic loading tests. However, the cooling tube or the interlayer in the divertor target is loaded by multi-axial stresses. To assess the LCF lifetime, the multi-axial plastic strain data must be converted into scalar values so that the simulation result can be directly compared with the measured data. Therefore, the equivalent plastic strain [23], $\varepsilon_{\mathrm{eq}}^{\mathrm{pl}}$, is evaluated in this work.

As shown in the previous study [22], significant plastic deformation accumulation occurs in the interlayer, while nearly no cyclic plastic deformation is accumulated in the cooling tube. Thus, in this work, it is focused on the impact of sweeping parameters on the accumulated equivalent plastic strain in the copper interlayer (the reference node is chosen in the middle of the interlayer at the plane of symmetry representing a most general case). Fig. 9 shows accumulated equivalent plastic strain in the copper interlayer as a function of time for various combinations of loading parameters. The accumulated equivalent plastic strains increase as the peak heat flux densities increase. The sweeping amplitude of $20 \mathrm{~cm}$ results in a faster accumulation of equivalent plastic strains than the sweeping amplitude of $5 \mathrm{~cm}$. With a sweeping frequency of $0.5 \mathrm{~Hz}$, the accumulated equivalent plastic strains are larger than that with a sweeping frequency of $1 \mathrm{~Hz}$. The increase of accumulated equivalent plastic strains is proportional to the temperature range in each cycle as shown in Table 4 .

Table 5 lists the predicted equivalent plastic range at the saturated thermal cycle as well as the fatigue lifetime of the interlayer. The fatigue lifetime was evaluated based on the the Manson-Coffin type relationship proposed in the ITER Materials handbook [24]. This relationship (Equation (11)) was used to fit the experimental fatigue test data ranging from 20 to $300^{\circ} \mathrm{C}$, in which no significant temperature dependence was shown. 


$$
\Delta \varepsilon_{\mathrm{t}}=\underbrace{49.89 N_{\mathrm{f}}^{-0.57}}_{\text {plastic }}+\underbrace{0.40 N_{\mathrm{f}}^{-0.075}}_{\text {elastic }}
$$

where $\Delta \varepsilon_{\mathrm{t}}$ is the total strain range, $N_{\mathrm{f}}$ is the cycles to failure.

As in the LCF regime, the contribution from the plastic component is dominant, only the LCF part of the equation was considered in the present assessment of the LCF lifetime. The second term in Equation (1) is omitted. The equivalent plastic strain range was used instead of the total strain range and it is equals to the half of the cyclic increment of accumulated equivalent plastic strains, see Fig. 9. Thus, the LCF lifetime, $N_{\mathrm{f}}$, can be accessed using Equation (11). One can find more details of fatigue lifetime calculations in the previous study [22].

The fatigue lifetime increases as the peak flux densities decrease. A greater fatigue lifetime is predicted if the sweeping amplitude decreases from $20 \mathrm{~cm}$ to $5 \mathrm{~cm}$. If the sweeping frequency is doubled (from $0.5 \mathrm{~Hz}$ to $1 \mathrm{~Hz}$ ), the fatigue lifetime is increased at least by a factor of 4 . As a result, increasing the sweeping frequency from $0.5 \mathrm{~Hz}$ to $1 \mathrm{~Hz}$ will increase the actual operating time for interlayer. Assuming the loading duration (pulse time) for a quasi-stationary case is $10 \mathrm{~s}$ (e.g. the slow transient case), when sweeping frequency of $1 \mathrm{~Hz}$ is applied, the number of thermal cycles is 10 times larger than that for stationary loading during the same operating time, as only one thermal cycle is considered for each pulse in the stationary case. For $0.5 \mathrm{~Hz}$, it is at least 5 times larger. Converting the fatigue lifetime to the number of pulses of $10 \mathrm{~s}$, for the peak heat flux density of $15 \mathrm{MW} / \mathrm{m}^{2}(20 \mathrm{~cm})$ sweeping the HHF load (15286 pulses) offers advantages for actual operating time compared to the non-sweeping stationary case (12553 pulses). With above mentioned parameters, sweeping can be applied as an emergency control action, in case a sudden increase of the thermal load on the divertor target is detected.

However, when the pulse time is assumed to be $7200 \mathrm{~s}$ (e.g. the stationary case in DEMO [25]), it will result in a much shorter actual operating time. Table 6 lists the number of pulses (one pulse length of $7200 \mathrm{~s}$ ) before LCF failure in the copper interlayer. For a peak heat flux density of $15 \mathrm{MW} / \mathrm{m}^{2}$ with $0.5 \mathrm{~Hz}$ and $20 \mathrm{~cm}$, converting the fatigue lifetime to the number of pulses of $7200 \mathrm{~s}$, the interlayer will fail after 21 pulses compared to 12553 pulses for non-sweeping case. Two further sweeping simulations for the peak heat flux density of $10 \mathrm{MW} / \mathrm{m}^{2}(1 \mathrm{~Hz}$ and $20 \mathrm{~cm})$ and the peak heat flux density of $15 \mathrm{MW} / \mathrm{m}^{2}(4 \mathrm{~Hz}$ and $20 \mathrm{~cm})$ are performed for studying the stationary case in ITER and DEMO. The predicted fatigue lifetime for the peak heat flux density of $10 \mathrm{MW} / \mathrm{m}^{2}(1 \mathrm{~Hz}$ and $20 \mathrm{~cm})$ is 1133500 cycles, which is 157 pulses by converting the fatigue lifetime to the number of pulses of $7200 \mathrm{~s}$ compared to 29991 pulses for the non-sweeping case. 
However, when the sweeping frequency is increased to $4 \mathrm{~Hz}$, the predicted fatigue lifetime for $15 \mathrm{MW} / \mathrm{m}^{2}$ with $20 \mathrm{~cm}$ is $1.99 \times 10^{8}$ cycles, which is 6906 pulses. Although it is roughly half of that in the non-sweeping case (12553 pulses), assuming 10 pulses per day, the lifetime will be nearly 2 years. Furthermore, it increases dramatically compared to the sweeping case with $0.5 \mathrm{~Hz}$. In this sense, sweeping can be applied as a steady state control scheme during normal operation with a frequency which is high enough.

Furthermore, the sweeping the HHF load in a larger area reduces the loading time for each divertor, which is an advantage for minimizing the thermal-induced material degradation (e.g. recrystallization) and the possible creep effect.

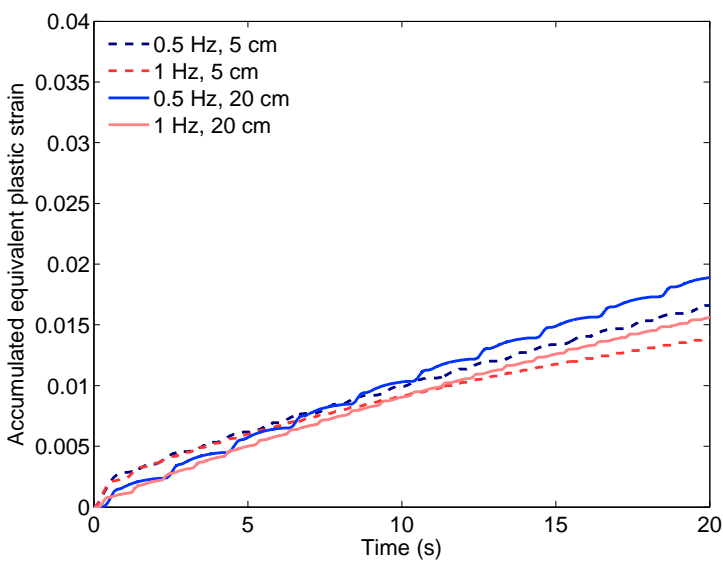

(a) Peak heat flux density: $15 \mathrm{MW} / \mathrm{m}^{2}$

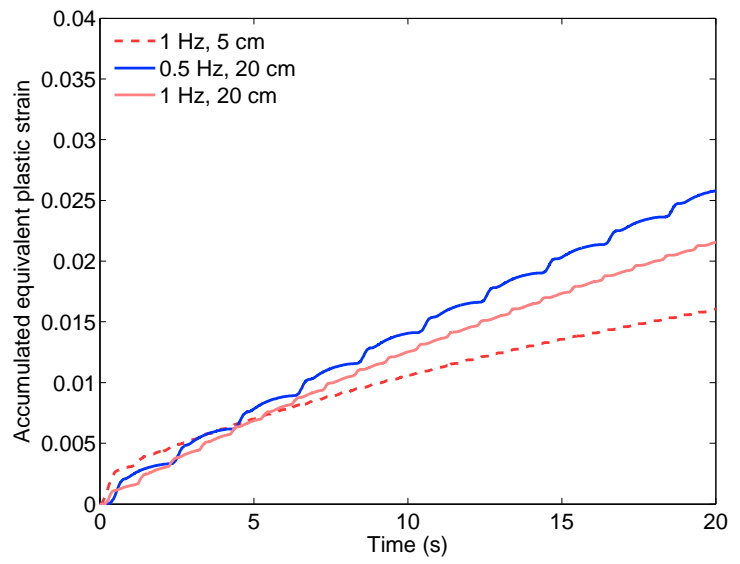

(b) Peak heat flux density: $20 \mathrm{MW} / \mathrm{m}^{2}$

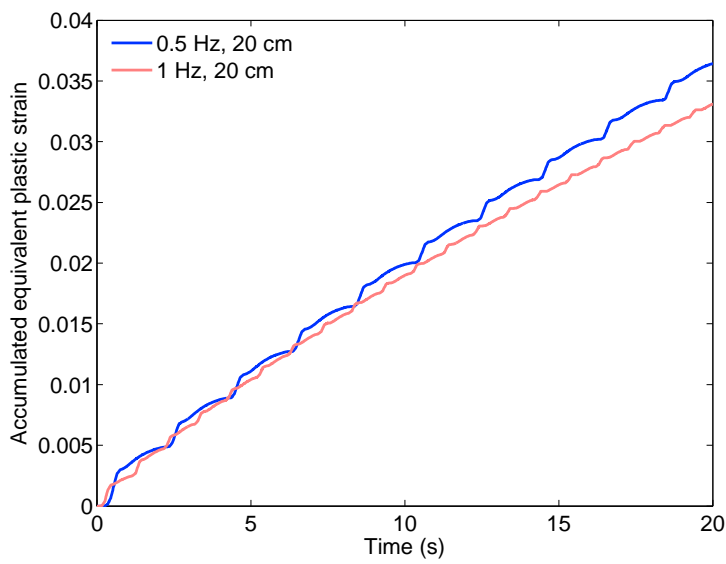

(c) Peak heat flux density: $30 \mathrm{MW} / \mathrm{m}^{2}$

Fig. 9. Accumulated equivalent plastic strain in the copper interlayer as a function of time for various combinations of loading parameters. 
Table 5. Predicted equivalent plastic strain range (\%) / fatigue lifetime ${ }^{a}$ in the copper interlayer.

\begin{tabular}{|c|c|c|c|c|}
\hline Peak heat flux density $\left(\mathrm{MW} / \mathrm{m}^{2}\right)$ & 10 & \multicolumn{3}{|c|}{15} \\
\hline Sweeping frequency $(\mathrm{Hz})$ & 1 & 0.5 & 1 & 4 \\
\hline Sweeping amplitude $(\mathrm{cm})$ & & & & \\
\hline 5 & & $0.064 / 119950$ & $0.021 / 852700$ & \\
\hline 20 & $0.018 / 1133500$ & $0.082 / 76430$ & $0.029 / 482960$ & $0.0009 / 1.99 \times 10^{8}$ \\
\hline Peak heat flux density $\left(\mathrm{MW} / \mathrm{m}^{2}\right)$ & 20 & & & 30 \\
\hline Sweeping frequency $(\mathrm{Hz})$ & 0.5 & 1 & 0.5 & 1 \\
\hline Sweeping amplitude (cm) & & & & \\
\hline 5 & - & $0.023 / 677900$ & - & - \\
\hline 20 & $0.112 / 44050$ & $0.040 / 271090$ & $0.159 / 24043$ & $0.064 / 118300$ \\
\hline
\end{tabular}

${ }^{a}$ Fatigue lifetime (allowed number of load cycles) was estimated from the reported fatigue data using plastic strain for unirradiated copper in the ITER Material Properties Handbook 24].

- critical heat flux is reached.

Table 6. Number of pulses (one pulse length of $7200 \mathrm{~s}$ ) before LCF failure in the copper interlayer.

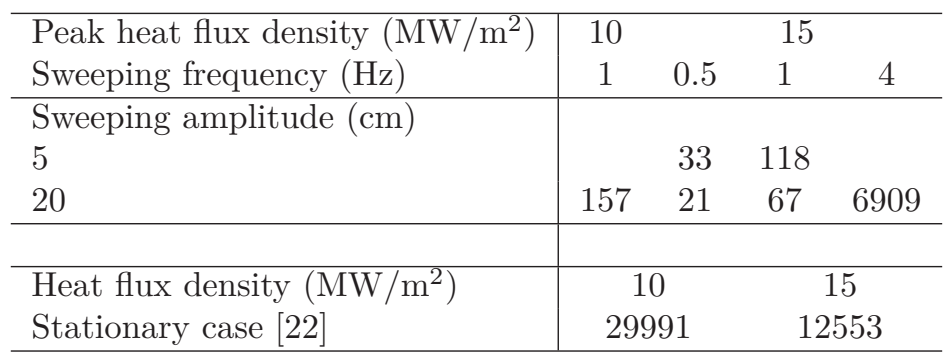

\section{Summary and conclusions}

In this paper, the results of an extensive computational study was reported which was carried out to assess the basic feasibility of the divertor heat flux sweeping technique in terms of the thermal and structural performance of a water-cooled tungsten mono-block target. Parametric finite element simulations demonstrated a significant thermal benefit of sweeping to reduce the peak temperature on the target, while the benefit in terms of structure-mechanical performance is shown only for certain loading scenarios. The sweeping amplitude and frequency turned out to have a considerable impact on the thermal efficiency of sweeping operation. The major predictions are summarized as follows:

1. The peak temperature decreases, when the sweeping amplitude or the sweeping frequency increases. The maximum heat flux to the coolant is significantly reduced by sweeping as well.

2. With an optimal combination of sweeping amplitude and frequency, even the extreme heat flux load of $30 \mathrm{MW} / \mathrm{m}^{2}$ could be accommodated without exceeding critical heat flux or armor melting point.

3. There is no general single trend between sweeping frequency (or amplitude) and the low cycle fatigue behavior. The impact depends on sweeping frequency and amplitude under consideration. 
4. For the parameters studied in this work, the increase of sweeping frequency (from 0.5 to $1 \mathrm{~Hz}$ ) or decrease of sweeping amplitude (from 20 to $5 \mathrm{~cm}$ ) has a beneficial effect on fatigue lifetime of the interlayer.

5. Sweeping offers advantages in terms of fatigue lifetime of interlayer as an emergency control action in case of a sudden increase of the thermal load on the divertor target.

6. Sweeping seems to be suitable as a steady state control scheme during normal operation if the sweeping frequency is high enough.

\section{Acknowledgement}

The authors are grateful to Dr. Fabio Crescenzi at ENEA for his providing us the data of heat transfer coefficient and critical heat flux. This work has been carried out within the framework of the EUROfusion Consortium and has received funding from the Euratom research and training programme 2014-2018 under grant agreement No 633053. The views and opinions expressed herein do not necessarily reflect those of the European Commission.

\section{References}

[1] M. Merola, D. Loesser, A. Martin, P. Chappuis, R. Mitteau, V. Komarov, R. Pitts, S. Gicquel, V. Barabash, L. Giancarli, J. Palmer, M. Nakahira, A. Loarte, D. Campbell, R. Eaton, A. Kukushkin, M. Sugihara, F. Zhang, C. Kim, R. Raffray, L. Ferrand, D. Yao, S. Sadakov, A. Furmanek, V. Rozov, T. Hirai, F. Escourbiac, T. Jokinen, B. Calcagno, S. Mori, ITER plasma-facing components, Fusion Engineering and Design 85 (2010) 2312-2322.

[2] A. Raffray, R. Nygren, D. Whyte, S. Abdel-Khalik, R. Doerner, F. Escourbiac, T. Evans, R. Goldston, D. Hoelzer, S. Konishi, P. Lorenzetto, M. Merola, R. Neu, P. Norajitra, R. Pitts, M. Rieth, M. Roedig, T. Rognlien, S. Suzuki, M. Tillack, C. Wong, High heat flux components - readiness to proceed from near term fusion systems to power plants, Fusion Engineering and Design 85 (2010) 93-108.

[3] G. Pintsuk, I. Bobin-Vastra, S. Constans, P. Gavila, M. Rödig, B. Riccardi, Qualification and post-mortem characterization of tungsten mock-ups exposed to cyclic high heat flux loading, Fusion Engineering and Design 88 (2013) 1858 - 1861.

[4] G. Pintsuk, M. Bednarek, P. Gavila, S. Gerzoskovitz, J. Linke, P. Lorenzetto, B. Riccardi, F. Escourbiac, Characterization of ITER tungsten qualification mock-ups exposed to high cyclic thermal loads, Fusion Engineering and Desigr doi:http://dx.doi.org/10.1016/j.fusengdes.2015.01.037

[5] J. H. You, A review on two previous divertor target concepts for DEMO: Mutual impact between structural design requirements and materials performance, Nuclear Fusion 55 (2015) 113026.

[6] E. Bertolini, Impact of JET experimental results and engineering development on the definition of the ITER design concept, Fusion Engineering and Design 27 (1995) 27 - 38.

[7] R. Albanese, G. Ambrosino, M. Ariola, A. Cenedese, F. Crisanti, G. D. Tommasi, M. Mattei, F. Piccolo, A. Pironti, F. Sartori, F. Villone, Design, implementation and test of the XSC extreme shape controller in JET, Fusion Engineering and Design 74 (2005) $627-632$. 
[8] G. Ambrosino, M. Ariola, G. De Tommasi, A. Pironti, F. Sartori, E. Joffrin, F. Villone, Plasma strike-point sweeping on JET tokamak with the eXtreme shape controller, Plasma Science, IEEE Transactions on 36 (2008) 834-840.

[9] R. Koenig, P. Grigull, K. McCormick, Y. Feng, J. Kisslinger, A. Komori, S. Masuzaki, K. Matsuoka, T. Obiki, N. Ohyabu, H. Renner, F. Sardei, F. Wagner, A. Werner, The divertor program in stellarators, Plasma Physics and Controlled Fusion 44 (2002) 2365.

[10] H. Renner, J. Boscary, H. Greuner, H. Grote, F. W. Hoffmann, J. Kisslinger, E. Strumberger, B. Mendelevitch, Divertor concept for the W7-X stellarator and mode of operation, Plasma Physics and Controlled Fusion 44 (2002) 1005.

[11] F. Maviglia, G. Federici, G. Strohmayer, R. Wenninger, C. Bachmann, R. Albanese, R. Ambrosino, M. Li, V. Loschiavo, J. You, L. Zani., Limitations of Transient Power Loads on DEMO and Analysis of Mitigation Techniques, 12th International Symposium on Fusion Nuclear Technology, Jeju, Korea, 2015 (accepted).

[12] T. Eich, A. Leonard, R. Pitts, W. Fundamenski, R. Goldston, T. Gray, A. Herrmann, A. Kirk, A. Kallenbach, O. Kardaun, A. Kukushkin, B. LaBombard, R. Maingi, M. Makowski, A. Scarabosio, B. Sieglin, J. Terry, A. Thornton, A. U. Team, J. E. Contributors, Scaling of the tokamak near the scrape-off layer H-mode power width and implications for ITER, Nuclear Fusion 53 (2013) 093031.

[13] F. Crescenzi, A. Moriani, S. Roccella, E. Visca, M. Richou, Water-cooled divertor target design study CuCrZr/W monoblock concept, EFDA report: WP13-DAS02-T02-D02 (2013).

[14] J. Lemaitre, J.-L. Chaboche, Mechanics of Solid Materials, 1st Edition, Cambridge University Press, 1994.

[15] P. J. Armstrong, C. O. Frederick, A mathematical representation of the multiaxial Bauschinger effect, G.E.G.B. Report $\mathrm{RD} / \mathrm{B} / \mathrm{N}(1966) 731$.

[16] J. Chaboche, Constitutive equations for cyclic plasticity and cyclic viscoplasticity, International Journal of Plasticity 5 (1989) 247-302.

[17] ITER structural design criteria for in-vessel components (SDC-IC) appendix A:Materials design limit data, ITER, (2001).

[18] J.-H. You, M. Miskiewicz, Material parameters of copper and CuCrZr alloy for cyclic plasticity at elevated temperatures, Journal of Nuclear Materials 373 (2008) 269-274.

[19] E. N. Sieder, G. E. Tate, Heat transfer and pressure drop of liquids in tubes, Industrial \& Engineering Chemistry 28 (1936) 1429-1435.

[20] J. Thom, W. Walker, T. Fallon, G. Reising, Boiling in sub-cooled water during flow up heated tubes or annuli., Proceedings of the Institution of Mechanical Engineers (London), 180: Pt 3C, 226-46(1965-66).

[21] M. Li, E. Werner, J.-H. You, Fracture mechanical analysis of tungsten armor failure of a water-cooled divertor target, Fusion Engineering and Design 89 (2014) 2716-2725.

[22] M. Li, E. Werner, J.-H. You, Low cycle fatigue behavior of ITER-like divertor target under DEMO-relevant operation conditions, Fusion Engineering and Design 90 (2015) 88-96.

[23] Abaqus analysis user's manual 6.12., Dassault Systémes Simulia Corp., Providence, RI, USA, 2012.

[24] ITER Material Properties Handbook, ITER Document No.G74 MA 16, 2005.

[25] G. Giruzzi, J. Artaud, M. Baruzzo, T. Bolzonella, E. Fable, L. Garzotti, I. Ivanova-Stanik, R. Kemp, D. King, M. Schneider, R. Stankiewicz, W. Stępniewski, P. Vincenzi, D. Ward, R. Zagórski, Modelling of pulsed and steady-state DEMO scenarios, Nuclear Fusion 55 (2015) 073002. 


\title{
Sweeping heat flux loads on divertor targets: thermal benefits and structural impacts
}

\author{
Muyuan $\mathrm{Li}^{\mathrm{a}}$, Francesco Maviglia ${ }^{\mathrm{b}}$, Gianfranco Federici ${ }^{\mathrm{b}}$, Jeong-Ha You ${ }^{\mathrm{a}, *}$ \\ ${ }^{a}$ Max-Planck-Institut für Plasmaphysik, Boltzmannstr.2, 85748 Garching, Germany \\ ${ }^{b}$ EUROfusion Consortium, PPPT Department, Boltzmannstr.2, 85748 Garching, Germany
}

\section{Highlights}

- Parametric simulations were performed to study the impact of strike-point sweeping.

- Temperature and heat flux to the coolant can be significantly reduced by sweeping.

- Higher sweeping frequency $(0.5-4 \mathrm{~Hz})$ offers advantages for fatigue lifetime.

- Sweeping is suitable for stationary loading if frequency is high enough (e.g. $4 \mathrm{~Hz}$ ).

\begin{abstract}
One possibility to mitigate the maximum high heat flux (HHF) load on the target is to sweep the position of the strike-point back and forth periodically in order to spread the peak thermal load over a wider width. The aim of this work is to investigate the thermal and structure-mechanical responses of a water-cooled tungsten mono-block target under cyclic HHF loads which are applied in sweeping modes. The study was performed by means of finite element analysis using an ITER-like target geometry. Extensive parametric simulations were carried out for a wide range of HHF loads and for selected sweeping amplitudes and frequencies, respectively. The simulation shows that the maximum temperature and the maximum heat flux to the coolant can be significantly reduced by sweeping. For the parameters studied in this work $(0.5-4 \mathrm{~Hz}, 5-20 \mathrm{~cm})$, higher sweeping frequency or smaller sweeping amplitude offers advantages in terms of fatigue lifetime of interlayer. Sweeping is suitable for the stationary loading if the sweeping frequency is high enough (e.g. $4 \mathrm{~Hz}$ ) based on the fatigue lifetime prediction of interlayer.
\end{abstract}

\footnotetext{
*Corresponding author. Tel.: +49 (0)89 3299 1373; fax:+49 (0)89 32991212.

Email address: you@ipp.mpg.de (Jeong-Ha You)
} 
keyword: DEMO, divertor, low cycle fatigue, high heat flux, plasma-facing component, strike-point sweeping

\section{Introduction}

In a tokamak-type fusion reactor, the plasma particles being detracted from the scrap-off layer onto the divertor target produce high heat flux (HHF) loads on the surface of the plasma facing target. The thermal loads are distributed highly heterogeneously over the poloidal positions of the target and locally concentrated around the strike-point which is the narrow intersection band of the separatrix with the target.

In the case of ITER divertor, the peak heat flux at the strike-point is predicted to reach $10 \mathrm{MW} / \mathrm{m}^{2}$ during stationary normal operation and even up to $20 \mathrm{MW} / \mathrm{m}^{2}$ during slow transient events which could last at least for a couple of seconds [1, 2]. For exhaustion of the thermal power, a water-cooled tungsten monoblock target equipped with copper alloy tubes was employed for the ITER divertor. The recent HHF qualification tests conducted on the prototypes of ITER divertor target revealed that substantial damages were produced in the tungsten armor (deep cracks, melting) and in the cooling tube (plastic deformation), when the applied heat flux load approached $20 \mathrm{MW} / \mathrm{m}^{2}[\underline{3}, 4]$. This result raises a critical concern in terms of the structural integrity and reliability of the target components under high transient thermal loads.

In the case of DEMO divertor target, the currently assumed HHF loads lie in the comparable range with those of the ITER divertor target. Therefore, the damage features mentioned above in relation to the ITER divertor target would still indicate critical design issues for the DEMO divertor target as well. Furthermore, the fracture failure risk of the armor, and potentially the tube as well, will become increasingly serious for the DEMO divertor target, as the neutron irradiation dose is expected to be at least an order of magnitude higher (3-6 dpa/fpy for the tungsten armor) than that of the ITER divertor target [5]. However, the technical feasibility to avoid or to mitigate the critical failure features seems to be quite limited. From the viewpoint of the current technological readiness, the metallurgical enhancement of the toughness of tungsten or copper alloy has been obviously stagnating. On the other hand, the safety margin of the target concept may not be sufficient in terms of structural design criteria, when the HHF load is increased toward $20 \mathrm{MW} / \mathrm{m}^{2}$. This trend is valid for the tungsten armor as well, although the armor is usually not regarded as actual structural part according to the conventional classification. Given such a highly demanding environment of structuremechanical loading that is nearly approaching the performance limit, there arises a need to reduce and keep under control the peak thermal load down to a safe level.

One of the potential (maybe more fundamental) solutions would be to control in real time the radiative 
loss of fusion power( in DEMO in excess of 90\%) while maintaining the divertor plasma in a detached regime constantly. However, the required technologies are by far distant from the engineering maturity. Even the underlying physics is only partly understood up to now that it will surely be only a long-term mission. How robust and reliable this control technique will be able to be is another concern besides its basic feasibility. A possible failure of any controlling sequence is likely to cause a sudden increase of heat flux up to $20 \mathrm{MW} / \mathrm{m}^{2}$, where irreversible damage may be produced. When the loss-of-detachment event is continually repeated due to the misfunction of the control system, the accumulated damage may eventually result in the global failure of a whole component within an unacceptably short operation lifetime.

Another possibility to mitigate the maximum HHF load on the target is to sweep the position of the strike-point back and forth periodically in order to spread the peak thermal load over a wider width. The concept of strike-point sweeping has already been successfully implemented into the JET experiment campaigns [6, 7, 8]. It was applied to the divertor design of the superconducting W7-X as well [9, 10]. A number of aspects need to be considered for evaluating the applicability of the sweeping concept [11]. For DEMO this technique could be applied either as an emergency control action, in case a sudden increase of the thermal load on the divertor target is detected, or as a steady state control scheme during normal operation. Extensive numerical estimations are being carried out to study the impact of various parameters on the thermal response of a target under sweeping operation, for instance, dimension of armor and heat sink, coolant inlet temperature, materials properties, and the time to coolant burn out. Additionally, to explore the feasibility of the sweeping technique for normal operation, comprehensive analyses are needed including required power, optimal amplitude and frequency of sweeping, impact on plasma shape and confinement quality, power dissipation due to the alternating currents induced in the neighboring superconductor coils and local temperature increase, and thermal fatigue of the materials due to the cyclic variation of thermal stresses. Among the above mentioned aspects, the impact of the sweeping is studied based on thermal and structure-mechanical responses in this work.

The aim of this work is to investigate the thermal and structure-mechanical responses of a water-cooled tungsten mono-block target under cyclic heat flux loads which are applied in sweeping modes. The focus is on the quantitative assessment of thermal benefits, namely, the reduction of peak temperature and maximum heat flux to the heat sink, and of structural risk caused by the thermal fatigue of the heat sink. The study was performed by means of finite element analysis using an ITER-like target geometry. Extensive parametric simulations were carried out for a wide range of HHF loads and for two selected sweeping amplitudes and frequencies, respectively. An obvious benefit of the sweeping scheme in thermal performance is demonstrated while the impact on the fatigue lifetime is addressed. 


\section{FE model}

\subsection{Geometry, FE mesh and materials}

Fig. 1] shows the assumed footprint of the heat flux power on the outer target according to the latest prediction for DEMO based on [12]. The target consists of a number of small rectangular tungsten block connecting by a cooling tube. Two neighboring blocks are separated by a thin gap ( $\sim 0.3 \mathrm{~mm})$. To study the influence of periodic strike point oscillation, the footprint of the heat flux power is swept at the surface of the targets along the axis direction of the cooling tube ( $x$-axis), see Fig. 2. The heat flux profile along the $y$-axis is assumed to be constant. The control point of the sweeping is set to be the 0 width position in Fig. 1. The sweeping amplitude is defined as the distance between the rightmost and leftmost positions of the control point during sweeping. One mono-block divertor is selected for the thermal analysis in this work, and the rightmost position of the control point lies on the right edge of the top surface of the selected monoblock divertor. The position where the maximum temperature occurs during sweeping is dependent on the sweeping amplitude and the sweeping frequency. According to a rough estimation from a $2 \mathrm{D}$ finite element (FE) simulation, the difference between the maximum temperatures of the targets and of the selected monoblock divertor is less than $100^{\circ} \mathrm{C}$ for loading conditions studied in this work. For simplicity, the selected mono-block divertor is used for all the loading combinations.

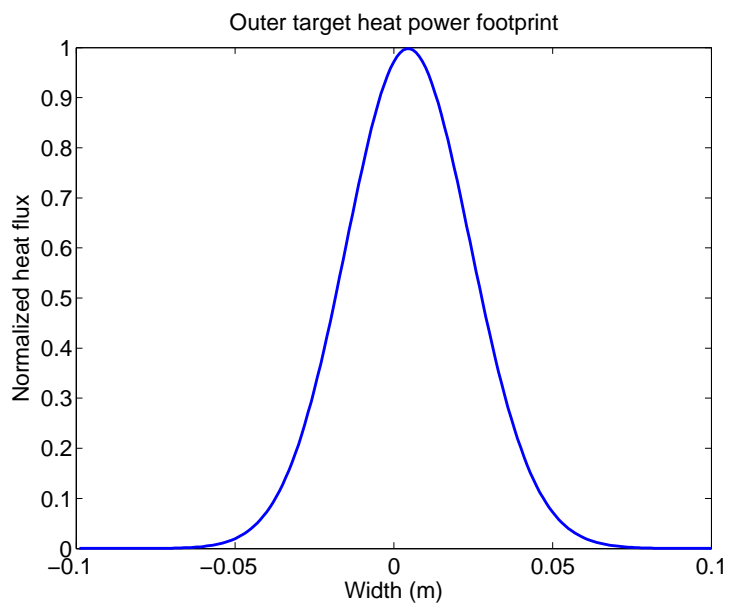

Fig. 1. The assumed footprint of the heat flux power on the outer target is according to the latest prediction for DEMO based on [12].

The PFC model considered for the FEM study is a water-cooled tungsten mono-block duplex structure consisting of a tungsten armor block and a copper alloy cooling tube (heat sink). The geometry, the FE mesh and the constituent materials of the considered model PFC are shown in Fig. 3, The tungsten armor block has dimensions of $23 \times 22 \times 4 \mathrm{~mm}$. The cooling tube has a thickness of $1.0 \mathrm{~mm}$ and an inner diameter 


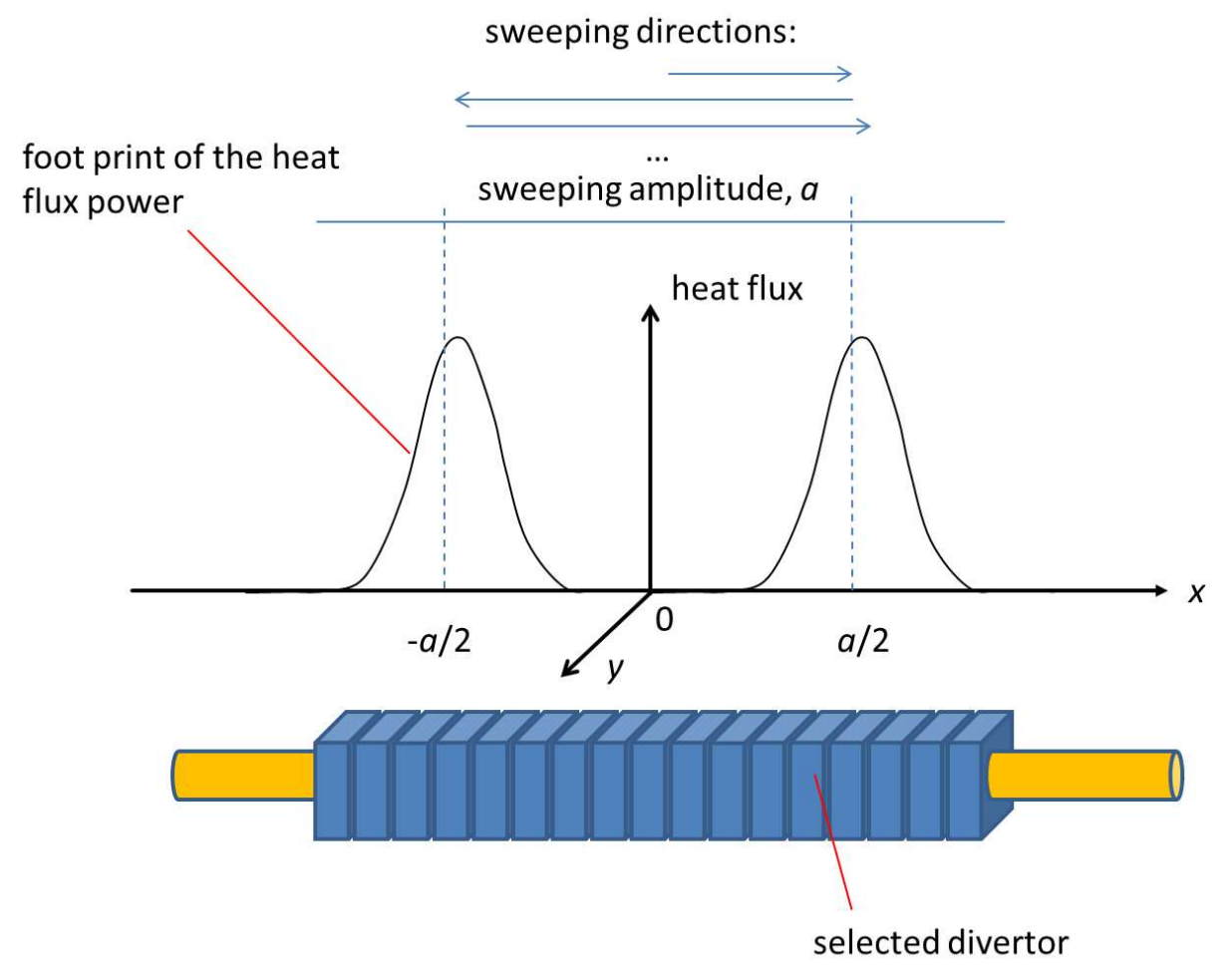

Fig. 2. Schematic drawing of sweeping the footprint of the heat flux power.

of $12 \mathrm{~mm}$. The thickness of the copper interlayer is $0.5 \mathrm{~mm}$. The geometry used here is based on the optimization of the geometry of the ITER tungsten divertor [13]. The commercial FEM code ABAQUS was employed for the numerical studies using quadratic brick elements of 20 nodes each. In total, there were 8496 finite elements. The mesh in the critical region of the component was refined.

At the selected mono-block divertor, the maximum temperature occurs at the left edge during sweeping. The nodes 1,2 and 3 at the left edge are therefore selected to characterize the maximum temperatures in tungsten block, between tungsten and copper, and between copper alloy and coolant water for sweeping cases. The simulation for a stationary case is also performed as a reference. In the stationary case, the heat flux peak is positioned at the middle line between the left and right edges of the top surface. The nodes 4 , 5 and 6 are used to characterize the maximum temperatures for the stationary case.

The thermo-mechanical simulations are based on data of several materials in the PFC model. Cross-rolled and stress-relieved tungsten was applied for the tungsten armor block. A precipitation-hardened copper alloy $(\mathrm{CuCrZr})$ was considered for the heat sink tube and soft-annealed copper constituted the interlayer. The Frederick-Armstrong constitutive model applied for copper and the copper alloy is based on the combination of non-linear isotropic and kinematic hardening laws [14, 15, 16]. Temperature-dependent material properties 


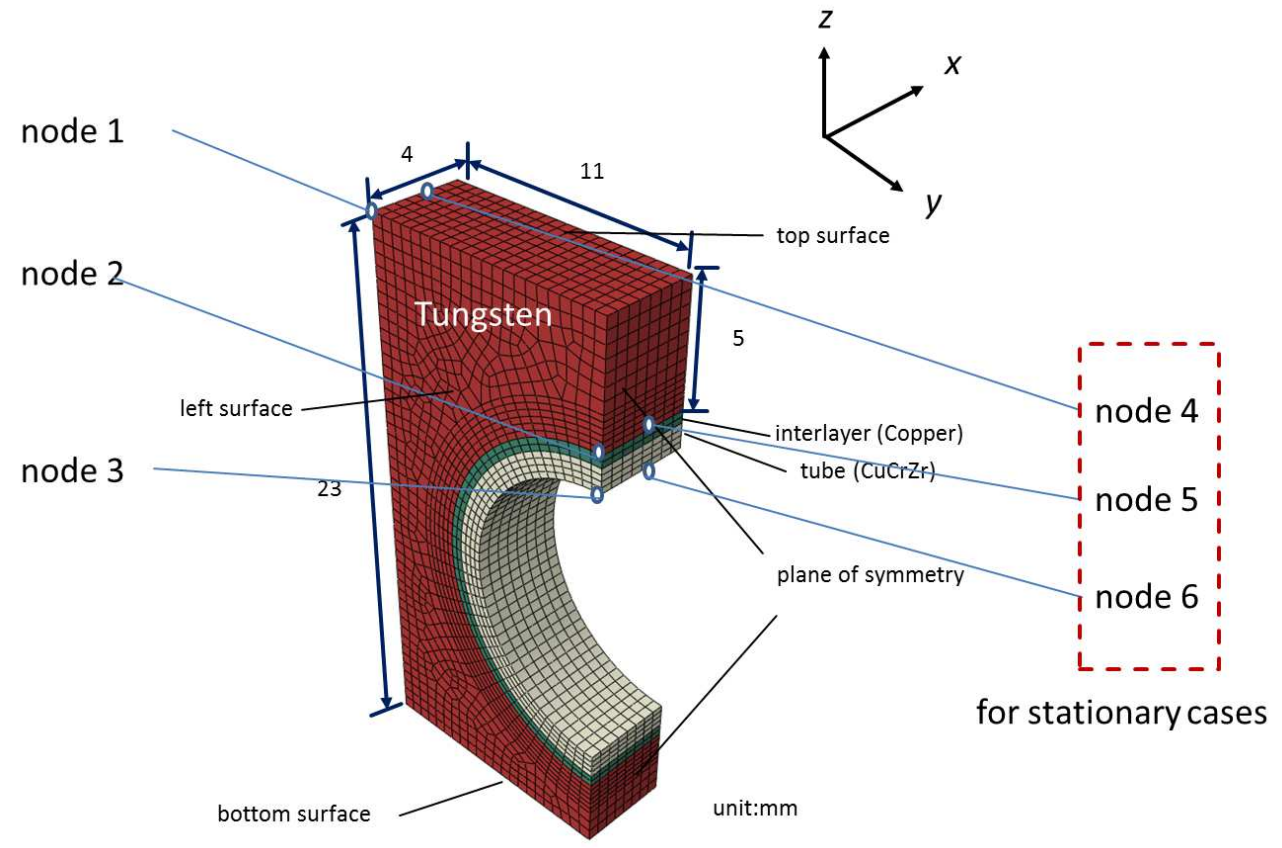

Fig. 3. The FE mesh of the mono-block divertor model. Due to symmetry only one half of the structure was considered.

are listed in Table 1at selected temperatures, corresponding to the operation temperatures for the considered materials. It should be noted that the materials are assumed to be unirradiated due to lack of data of irradiated materials.

\subsection{Loads and boundary conditions}

The peak heat flux densities of $15 \mathrm{MW} / \mathrm{m}^{2}, 20 \mathrm{MW} / \mathrm{m}^{2}$ and $30 \mathrm{MW} / \mathrm{m}^{2}$ are applied in this study. Before the HHF load is applied, the PFC is assumed to have a uniform temperature (coolant temperature) without any residual stress. For a parametric study, the sweeping amplitudes of $5 \mathrm{~cm}$ and $20 \mathrm{~cm}$ are chosen. The sweeping frequency varies from $1 \mathrm{~Hz}$ to $0.5 \mathrm{~Hz}$. Two further simulations that consider $10 \mathrm{MW} / \mathrm{m}^{2}$ and $4 \mathrm{~Hz}$ are also performed to study the vadilty of applying sweeping as a steady state control scheme during normal operation.

The heat transfer coefficient (HTC) between the inner wall of the heat sink tube and the coolant water is plotted in Fig. 4. It is calculated using SIEDER/TATE [19] and CEA/THOM [20] correlations for forced convection and subcooled boiling regimes, respectively. The pressure of the coolant water is $5 \mathrm{MPa}$. The coolant water velocity is $12 \mathrm{~m} / \mathrm{s}$. The temperature of the coolant water is $200^{\circ} \mathrm{C}$. A swirl tape (thickness: $0.8 \mathrm{~mm}$, twist ratio: 2) in the tube was assumed in the calculation of heat transfer coefficient. 
Table 1. Properties of the considered materials at selected temperatures [17, 18].

\begin{tabular}{|c|c|c|c|c|c|c|c|}
\hline & \multicolumn{3}{|c|}{ Tungsten $^{1}$} & \multicolumn{2}{|c|}{$\mathrm{CuCrZr}^{2}$} & \multicolumn{2}{|c|}{ Copper $^{3}$} \\
\hline & $20^{\circ} \mathrm{C}$ & $400^{\circ} \mathrm{C}$ & $1200^{\circ} \mathrm{C}$ & $20^{\circ} \mathrm{C}$ & $400^{\circ} \mathrm{C}$ & $20^{\circ} \mathrm{C}$ & $400^{\circ} \mathrm{C}$ \\
\hline Young's modulus (GPa) & 398 & 393 & 356 & 115 & 106 & 115 & 95 \\
\hline Yield stress (MPa) & 1385 & 1100 & 346 & 273 & 238 & 3 & 3 \\
\hline$Q^{*}(\mathrm{MPa})$ & & & & -43 & -68 & 76 & 36 \\
\hline$b^{*}$ & & & & 6 & 10 & 8 & 25 \\
\hline$C^{*}(\mathrm{MPa})$ & & & & 148575 & 117500 & 64257 & 31461 \\
\hline$\gamma^{*}$ & & & & 930 & 1023 & 888 & 952 \\
\hline Heat conductivity $(\mathrm{W} / \mathrm{mK})$ & 175 & 140 & 105 & 318 & 347 & 379 & 352 \\
\hline $\begin{array}{l}\text { Coefficient of } \\
\text { thermal expansion }\left(10^{-6} / \mathrm{K}\right)\end{array}$ & 4.5 & 4.6 & 5.3 & 16.7 & 17.8 & 17.8 & 18.1 \\
\hline
\end{tabular}

${ }_{1}$ Rolled and stress-relieved state.

2 Precipitation-hardened state, the reference alloy: Elmedur-X (code: $\mathrm{CuCr} 1 \mathrm{Zr}, \mathrm{Cr}: 0.8 \%, \mathrm{Zr}: 0.08 \%$ ).

${ }^{3}$ Softened by annealing at $700^{\circ} \mathrm{C}$ for $1 \mathrm{~h}$.

* Material parameters entering the Frederick-Armstrong constitutive model [18].

At two ends of the cooling tube, a planar axial displacement constraint is given. 


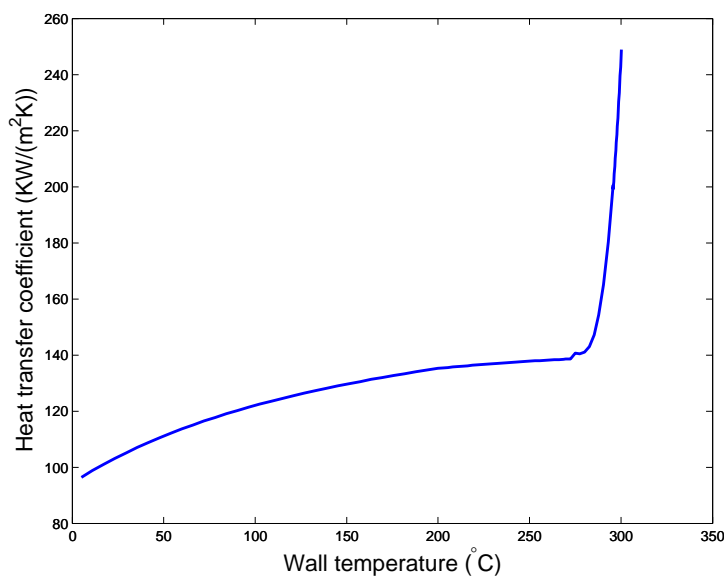

Fig. 4. Heat transfer coefficient between the inner wall of the heat sink tube and the coolant water. The coolant water velocity is $12 \mathrm{~m} / \mathrm{s}$. Pressure of the coolant water is $5 \mathrm{MPa}$. The temperature of the coolant water is $200^{\circ} \mathrm{C}$. A swirl tape (thickness: $0.8 \mathrm{~mm}$, twist ratio: 2) in the tube was assumed.

\section{Results and discussion}

\subsection{Critical heat flux}

The simulations were conducted with different sweeping frequencies and sweeping amplitudes. A higher sweeping frequency leads more thermal cycles within the same time but less loading time for each thermal cycle. Increasing the sweeping amplitude results in spreading the energy in a larger area, i.e. the energy input is reduced for each mono-block. Table 2 lists the heat flux densities at copper alloy-water interface (at node 3). The critical heat flux density is $25.3 \mathrm{MW} / \mathrm{m}^{2}$ at wall temperature of $300^{\circ} \mathrm{C}$ for a coolant temperature of $200^{\circ} \mathrm{C}$ calculated using modified Tong 75 correlation according to the CEA formulation. When the heat flux to the coolant is above the critical value, the coolant loses heat removal capability. This effect is not included in the simulations. In the simulation, if the wall temperature is higher than $300^{\circ} \mathrm{C}$, the

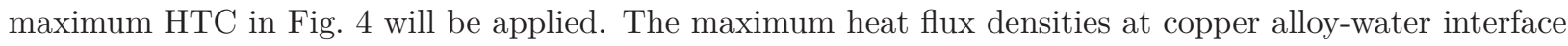
of stationary cases for $20 \mathrm{MW} / \mathrm{m}^{2}$ and $30 \mathrm{MW} / \mathrm{m}^{2}$ as well as sweeping cases with a sweeping amplitude of $5 \mathrm{~cm}$ for $30 \mathrm{MW} / \mathrm{m}^{2}$ are much larger than the critical heat flux and not listed here. Those results are not unrealistic due to the fact that the HTC above the CHF is not correctly implemented in the simulations. In general, this work focuses on the cases in which the maximum heat flux to the coolant is below the CHF. For the stationary case of $15 \mathrm{MW} / \mathrm{m}^{2}$, the maximum heat flux density $\left(25.4 \mathrm{MW} / \mathrm{m}^{2}\right)$ is slightly above the critical value $\left(25.3 \mathrm{MW} / \mathrm{m}^{2}\right)$, but considering that this only occurs in a limited area of the wall surface, the result is acceptable as a reference. 
When a sweeping amplitude of $20 \mathrm{~cm}$ is applied, the maximum heat flux density to the coolant can be reduced below the critical value. For the best combination of sweeping amplitude and frequency (20 cm and $1 \mathrm{~Hz}$ ) listed in Table 2, the maximum heat flux density to the coolant can be reduced by a factor of 4. Furthermore, as the loading time on one mono-block divertor is significantly reduced by sweeping, the damage induced by a sudden increase of the heat flux density will be smaller than that in the stationary cases.

Table 2. Maximum heat flux density $\left(\mathrm{MW} / \mathrm{m}^{2}\right)$ temperature $\left.\left({ }^{\circ} \mathrm{C}\right)\right]$ at copper alloy-water interface (at node 3$)$.

\begin{tabular}{|c|c|c|c|c|c|c|}
\hline Peak heat flux density $\left(\mathrm{MW} / \mathrm{m}^{2}\right)$ & \multicolumn{2}{|c|}{15} & \multicolumn{2}{|c|}{20} & \multicolumn{2}{|c|}{30} \\
\hline Sweeping frequency $(\mathrm{Hz})$ & 0.5 & 1 & 0.5 & 1 & 0.5 & 1 \\
\hline Sweeping amplitude (cm) & & & & & & \\
\hline 5 & $20.6(297)$ & $18.2(295)$ & - & $24.8(300)$ & - & - \\
\hline 20 & $8.6(262)$ & $6.0(243)$ & $11.3(280)$ & $7.8(257)$ & $19.0(295)$ & $11.6(281)$ \\
\hline Stationary case & \multicolumn{2}{|c|}{$25.4(302)$} & \multicolumn{2}{|l|}{-} & \multicolumn{2}{|c|}{ - } \\
\hline
\end{tabular}

\subsection{Temperature}

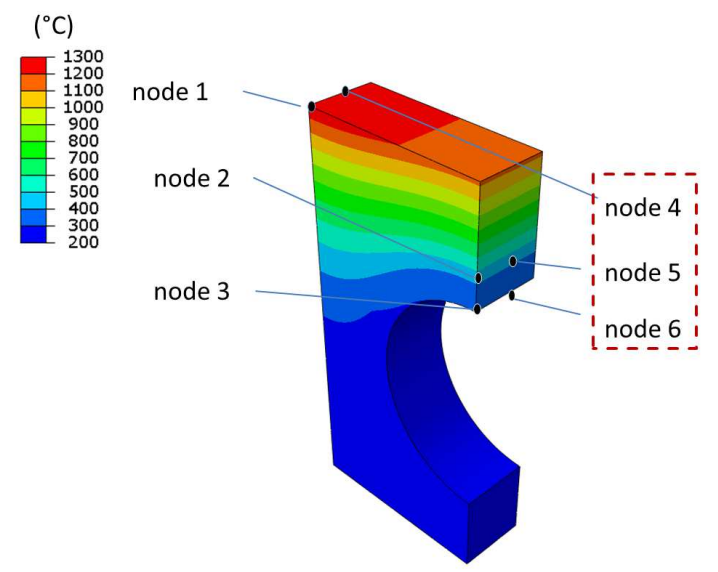

Fig. 5. Temperature distribution for a stationary heat flux of $15 \mathrm{MW} / \mathrm{m}^{2}$. The locations of the reference nodes are also illustrated.

In Fig. 5. a typical temperature distribution of the divertor under HHF load is shown, where the locations of the reference nodes are also illustrated. Fig. 6] shows temperature and heat flux density at node 1 as a function of time for a peak heat flux density of $15 \mathrm{MW} / \mathrm{m}^{2}$ with a sweeping frequency of $1 \mathrm{~Hz}$ and a sweeping amplitude of $5 \mathrm{~cm}$. Two peaks of heat flux density at node 1 in one thermal cycle are quite close to each other, since the selected mono-block is located near the edge of the sweeping area. The peak temperature occurs shortly after the occurrence of the second peak of the heat flux density. After a few seconds, a 


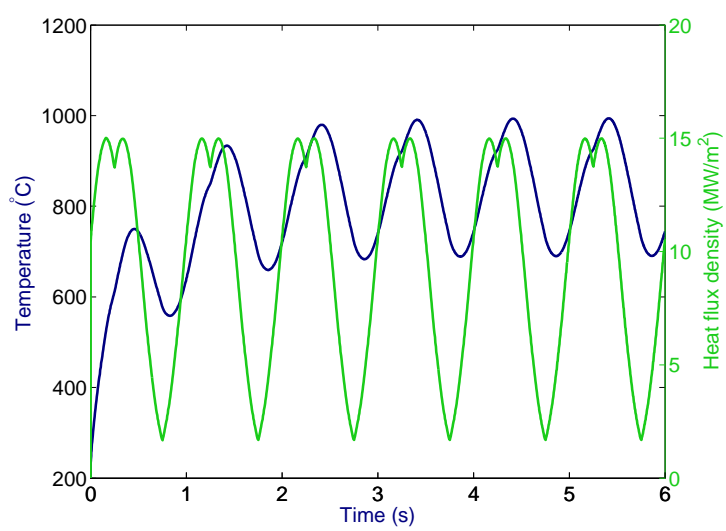

Fig. 6. Temperature and heat flux density at node 1 as a function of time for a peak heat flux density of $15 \mathrm{MW} / \mathrm{m}^{2}$ with sweeping frequency of $1 \mathrm{~Hz}$ and sweeping amplitude of $5 \mathrm{~cm}$.

saturated thermal cycle is observed.

Table 3. Maximum / Minimum (amplitude) temperatures $\left({ }^{\circ} \mathrm{C}\right)$ at node 1 in the saturated thermal cycle.

\begin{tabular}{|c|c|c|c|c|}
\hline Sweeping amplitude $(\mathrm{cm})$ & \multicolumn{2}{|c|}{5} & \multicolumn{2}{|c|}{20} \\
\hline Sweeping frequency $(\mathrm{Hz})$ & 0.5 & 1 & 0.5 & 1 \\
\hline Peak heat flux density $\left(\mathrm{MW} / \mathrm{m}^{2}\right)$ & & & & \\
\hline & $1076 / 606(470)$ & $993 / 698(295)$ & $645 / 244(401)$ & $551 / 271(280)$ \\
\hline Maximum temperature (stationary) & & & & \\
\hline 20 & - & $1281 / 896(385)$ & $800 / 247(553)$ & $671 / 294(377)$ \\
\hline $\begin{array}{l}\text { Maximum temperature (stationary) } \\
30 \\
\text { Maximum temperature (stationary) }\end{array}$ & - & $x^{\prime}$ & $1119 / 286(833)$ & $920 / 342(578)$ \\
\hline
\end{tabular}

- critical heat flux is reached.

Fig. 7 shows the temperature at node 1 for peak heat flux densities of $15 \mathrm{MW} / \mathrm{m}^{2}, 20 \mathrm{MW} / \mathrm{m}^{2}$ and $30 \mathrm{MW} / \mathrm{m}^{2}$. The temperature is much higher for a sweeping amplitude of $5 \mathrm{~cm}$ than $20 \mathrm{~cm}$. When the sweeping frequency increases, the peak temperature decreases. As a result, the peak temperature at the top surface of the mono-block can be reduced by increasing either the sweeping amplitude or the sweeping frequency. However, increasing the sweeping amplitude will be limited by the geometry of divertor target. A higher sweeping frequency will require more thermal cycles during the operation, but at the same time, it reduces the temperature variation as well as the loading time in each thermal cycle. The former will certainly shorten the actual operating time but the later will enlarge the allowed number of load cycles (fatigue lifetime). The study of impact of increasing sweeping frequency on LCF behavior will be shown later in this section.

Table 3 gives maximum and minimum temperatures at node 1 in the saturated thermal cycle. When 


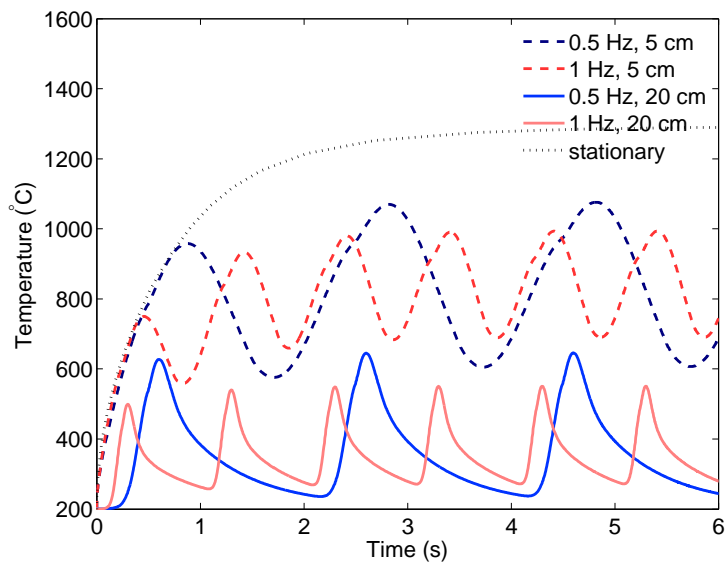

(a) Peak heat flux density: $15 \mathrm{MW} / \mathrm{m}^{2}$

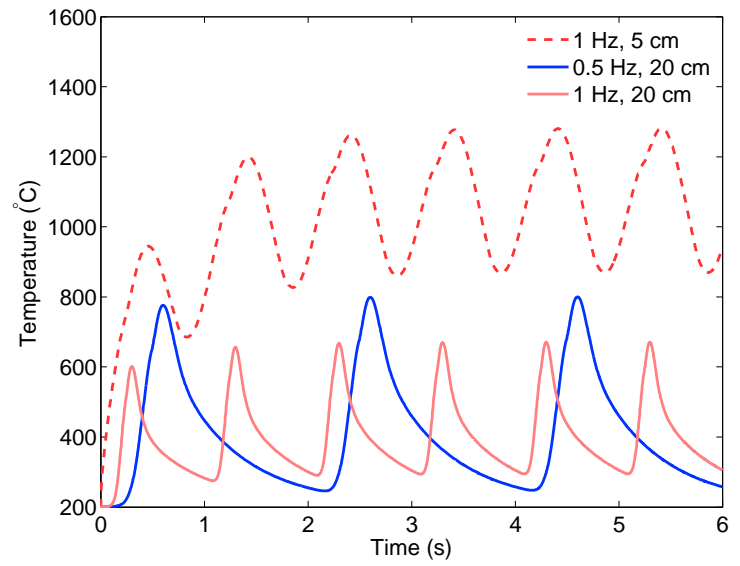

(b) Peak heat flux density: $20 \mathrm{MW} / \mathrm{m}^{2}$

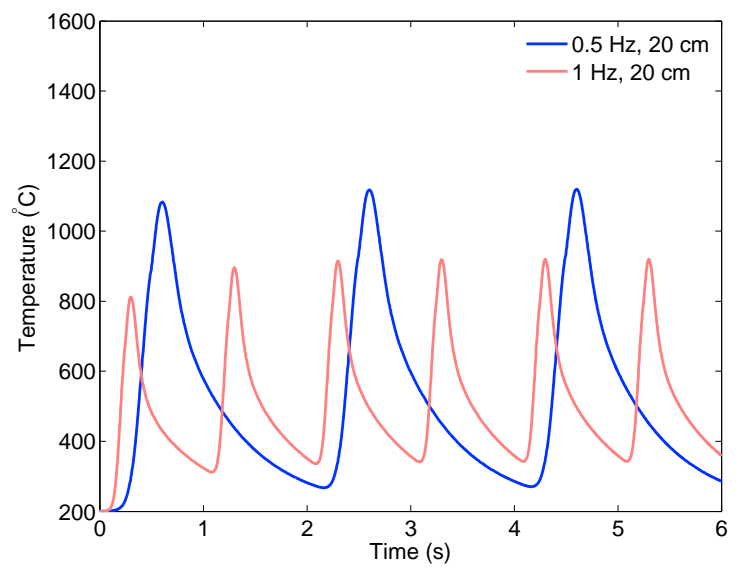

(c) Peak heat flux density: $30 \mathrm{MW} / \mathrm{m}^{2}$

Fig. 7. Temperature at node 1 as a function of time for different peak heat flux densities.

the sweeping frequency increases from 0.5 to $1 \mathrm{~Hz}$, the maximum temperature decreases and the minimum temperature increases. As a result, the temperature amplitudes drop more than $30 \%$. When the sweeping amplitude of $20 \mathrm{~cm}$ is applied instead of $5 \mathrm{~cm}$, both the maximum and the minimum temperatures decrease, and the reduction in the temperature variation amplitude is less than $15 \%$, which deceases with increasing the frequency. For the peak heat flux density of $20 \mathrm{MW} / \mathrm{m}^{2}(1 \mathrm{~Hz}$ and $5 \mathrm{~cm})$ and $30 \mathrm{MW} / \mathrm{m}^{2}(0.5 \mathrm{~Hz}$ and $20 \mathrm{~cm})$, the maximum temperatures enter the crystallization temperature range of tungsten $\left(1100-1400^{\circ} \mathrm{C}\right)$. When tungsten at the surface layer is recrystallized, the strength of tungsten is significantly reduced, and major cracks have been observed in the heat flux tests of divertors [3]. When there is no recrystallized layer at the surface, the brittle cracking is not critical in the tungsten armor block [21].

Fig. 8 shows the temperature at node 2 for peak heat flux densities of $15 \mathrm{MW} / \mathrm{m}^{2}, 20 \mathrm{MW} / \mathrm{m}^{2}$ and $30 \mathrm{MW} / \mathrm{m}^{2}$. The impact of the sweeping amplitude and the sweeping frequency on the temperature is 


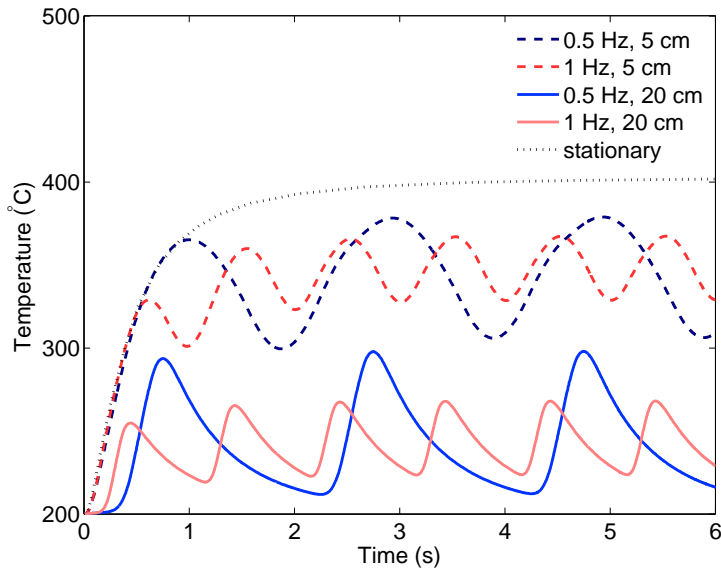

(a) Peak heat flux density: $15 \mathrm{MW} / \mathrm{m}^{2}$

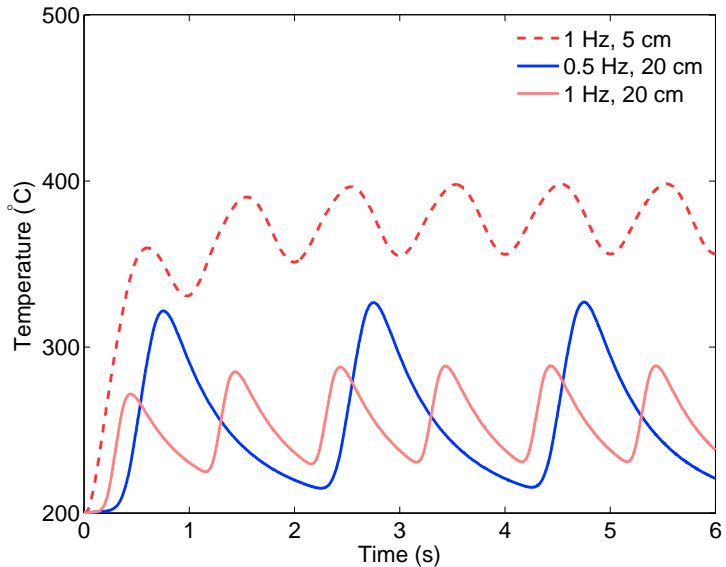

(b) Peak heat flux density: $20 \mathrm{MW} / \mathrm{m}^{2}$

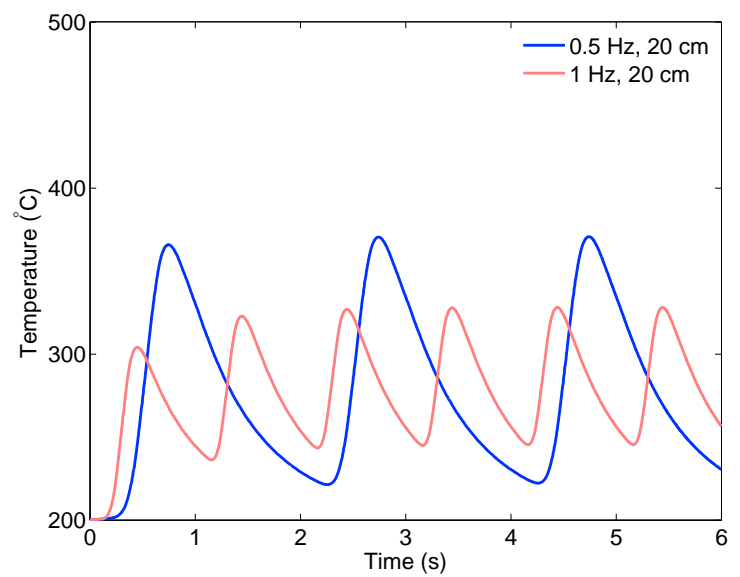

(c) Peak heat flux density: $30 \mathrm{MW} / \mathrm{m}^{2}$

Fig. 8. Temperature at node 2 as a function of time.

similar. The maximum temperature in the saturated thermal cycle can be reduced below $400^{\circ} \mathrm{C}$ by applying a sweeping amplitude of $20 \mathrm{~cm}$ for the peak heat flux density of up to $30 \mathrm{MW} / \mathrm{m}^{2}$. The high temperature (above $400^{\circ} \mathrm{C}$ ) is critical at the interface between tungsten armor block and copper interlayer, as the copper will become softer. Maximum and minimum temperatures at node 2 are listed in Table 4 . Compared to the situation at the top surface, the temperature variation at node 2 is less significant and its amplitude is less than $20 \%$ of that at node 1 . However, the temperature variation in the copper interlayer is more critical, since a large amount of plastic deformation will be generated due to the temperature variation leading to LCF failure 22]. Different from the trend of maximum temperatures at the top surface, the temperature amplitude increases, if the sweeping amplitude increase from $5 \mathrm{~cm}$ to $20 \mathrm{~cm}$. This is because for the sweeping amplitude of $20 \mathrm{~cm}$, the selected mono-block can be cooled to a lower temperature. 
Table 4. Maximum / Minimum (amplitude) temperatures $\left({ }^{\circ} \mathrm{C}\right)$ at node 2 in the saturated thermal cycle.

\begin{tabular}{|c|c|c|c|c|}
\hline Sweeping amplitude $(\mathrm{cm})$ & \multicolumn{2}{|c|}{5} & \multicolumn{2}{|c|}{20} \\
\hline Sweeping frequency $(\mathrm{Hz})$ & 0.5 & 1 & 0.5 & 1 \\
\hline $\begin{array}{l}\text { Peak heat flux density }\left(\mathrm{MW} / \mathrm{m}^{2}\right) \\
15\end{array}$ & $378 / 306(72)$ & $367 / 328(39)$ & $297 / 216(81)$ & $268 / 223(45)$ \\
\hline Maximum temperature (stationary) & & & & \\
\hline 20 & - & $398 / 355(43)$ & $327 / 215(112)$ & $288 / 230(58)$ \\
\hline Maximum temperature (stationary) & & & & \\
\hline 30 & - & - & $370 / 230(140)$ & $328 / 245(83)$ \\
\hline Maximum temperature (stationary) & & & & \\
\hline
\end{tabular}

\subsection{Fatigue lifetime}

In the literature, most of the LCF data are obtained from a uniaxial cyclic loading tests. However, the cooling tube or the interlayer in the divertor target is loaded by multi-axial stresses. To assess the LCF lifetime, the multi-axial plastic strain data must be converted into scalar values so that the simulation result can be directly compared with the measured data. Therefore, the equivalent plastic strain [23], $\varepsilon_{\mathrm{eq}}^{\mathrm{pl}}$, is evaluated in this work.

As shown in the previous study [22], significant plastic deformation accumulation occurs in the interlayer, while nearly no cyclic plastic deformation is accumulated in the cooling tube. Thus, in this work, it is focused on the impact of sweeping parameters on the accumulated equivalent plastic strain in the copper interlayer (the reference node is chosen in the middle of the interlayer at the plane of symmetry representing a most general case). Fig. 9 shows accumulated equivalent plastic strain in the copper interlayer as a function of time for various combinations of loading parameters. The accumulated equivalent plastic strains increase as the peak heat flux densities increase. The sweeping amplitude of $20 \mathrm{~cm}$ results in a faster accumulation of equivalent plastic strains than the sweeping amplitude of $5 \mathrm{~cm}$. With a sweeping frequency of $0.5 \mathrm{~Hz}$, the accumulated equivalent plastic strains are larger than that with a sweeping frequency of $1 \mathrm{~Hz}$. The increase of accumulated equivalent plastic strains is proportional to the temperature range in each cycle as shown in Table 4 .

Table 5 lists the predicted equivalent plastic range at the saturated thermal cycle as well as the fatigue lifetime of the interlayer. The fatigue lifetime was evaluated based on the the Manson-Coffin type relationship proposed in the ITER Materials handbook [24]. This relationship (Equation (11)) was used to fit the experimental fatigue test data ranging from 20 to $300^{\circ} \mathrm{C}$, in which no significant temperature dependence was shown. 


$$
\Delta \varepsilon_{\mathrm{t}}=\underbrace{49.89 N_{\mathrm{f}}^{-0.57}}_{\text {plastic }}+\underbrace{0.40 N_{\mathrm{f}}^{-0.075}}_{\text {elastic }}
$$

where $\Delta \varepsilon_{\mathrm{t}}$ is the total strain range, $N_{\mathrm{f}}$ is the cycles to failure.

As in the LCF regime, the contribution from the plastic component is dominant, only the LCF part of the equation was considered in the present assessment of the LCF lifetime. The second term in Equation (1) is omitted. The equivalent plastic strain range was used instead of the total strain range and it is equals to the half of the cyclic increment of accumulated equivalent plastic strains, see Fig. 9. Thus, the LCF lifetime, $N_{\mathrm{f}}$, can be accessed using Equation (11). One can find more details of fatigue lifetime calculations in the previous study [22].

The fatigue lifetime increases as the peak flux densities decrease. A greater fatigue lifetime is predicted if the sweeping amplitude decreases from $20 \mathrm{~cm}$ to $5 \mathrm{~cm}$. If the sweeping frequency is doubled (from $0.5 \mathrm{~Hz}$ to $1 \mathrm{~Hz}$ ), the fatigue lifetime is increased at least by a factor of 4 . As a result, increasing the sweeping frequency from $0.5 \mathrm{~Hz}$ to $1 \mathrm{~Hz}$ will increase the actual operating time for interlayer. Assuming the loading duration (pulse time) for a quasi-stationary case is $10 \mathrm{~s}$ (e.g. the slow transient case), when sweeping frequency of $1 \mathrm{~Hz}$ is applied, the number of thermal cycles is 10 times larger than that for stationary loading during the same operating time, as only one thermal cycle is considered for each pulse in the stationary case. For $0.5 \mathrm{~Hz}$, it is at least 5 times larger. Converting the fatigue lifetime to the number of pulses of $10 \mathrm{~s}$, for the peak heat flux density of $15 \mathrm{MW} / \mathrm{m}^{2}(20 \mathrm{~cm})$ sweeping the HHF load (15286 pulses) offers advantages for actual operating time compared to the non-sweeping stationary case (12553 pulses). With above mentioned parameters, sweeping can be applied as an emergency control action, in case a sudden increase of the thermal load on the divertor target is detected.

However, when the pulse time is assumed to be $7200 \mathrm{~s}$ (e.g. the stationary case in DEMO [25]), it will result in a much shorter actual operating time. Table 6 lists the number of pulses (one pulse length of $7200 \mathrm{~s}$ ) before LCF failure in the copper interlayer. For a peak heat flux density of $15 \mathrm{MW} / \mathrm{m}^{2}$ with $0.5 \mathrm{~Hz}$ and $20 \mathrm{~cm}$, converting the fatigue lifetime to the number of pulses of $7200 \mathrm{~s}$, the interlayer will fail after 21 pulses compared to 12553 pulses for non-sweeping case. Two further sweeping simulations for the peak heat flux density of $10 \mathrm{MW} / \mathrm{m}^{2}(1 \mathrm{~Hz}$ and $20 \mathrm{~cm})$ and the peak heat flux density of $15 \mathrm{MW} / \mathrm{m}^{2}(4 \mathrm{~Hz}$ and $20 \mathrm{~cm})$ are performed for studying the stationary case in ITER and DEMO. The predicted fatigue lifetime for the peak heat flux density of $10 \mathrm{MW} / \mathrm{m}^{2}(1 \mathrm{~Hz}$ and $20 \mathrm{~cm})$ is 1133500 cycles, which is 157 pulses by converting the fatigue lifetime to the number of pulses of $7200 \mathrm{~s}$ compared to 29991 pulses for the non-sweeping case. 
However, when the sweeping frequency is increased to $4 \mathrm{~Hz}$, the predicted fatigue lifetime for $15 \mathrm{MW} / \mathrm{m}^{2}$ with $20 \mathrm{~cm}$ is $1.99 \times 10^{8}$ cycles, which is 6906 pulses. Although it is roughly half of that in the non-sweeping case (12553 pulses), assuming 10 pulses per day, the lifetime will be nearly 2 years. Furthermore, it increases dramatically compared to the sweeping case with $0.5 \mathrm{~Hz}$. In this sense, sweeping can be applied as a steady state control scheme during normal operation with a frequency which is high enough.

Furthermore, the sweeping the HHF load in a larger area reduces the loading time for each divertor, which is an advantage for minimizing the thermal-induced material degradation (e.g. recrystallization) and the possible creep effect.

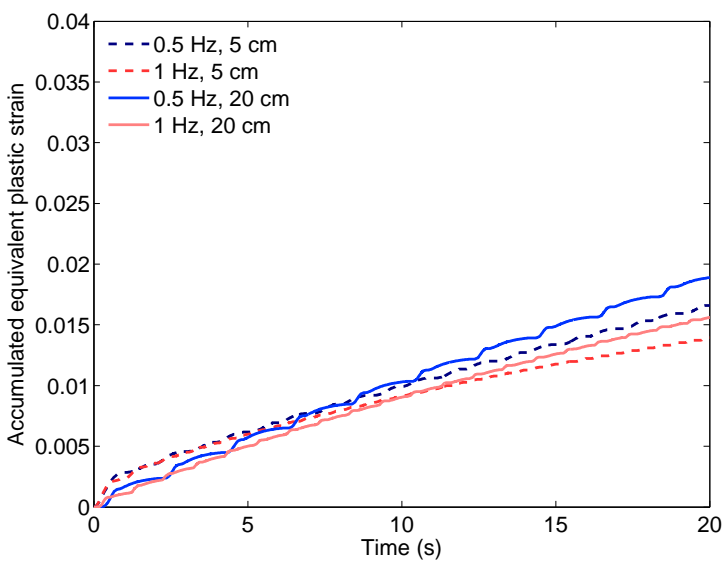

(a) Peak heat flux density: $15 \mathrm{MW} / \mathrm{m}^{2}$

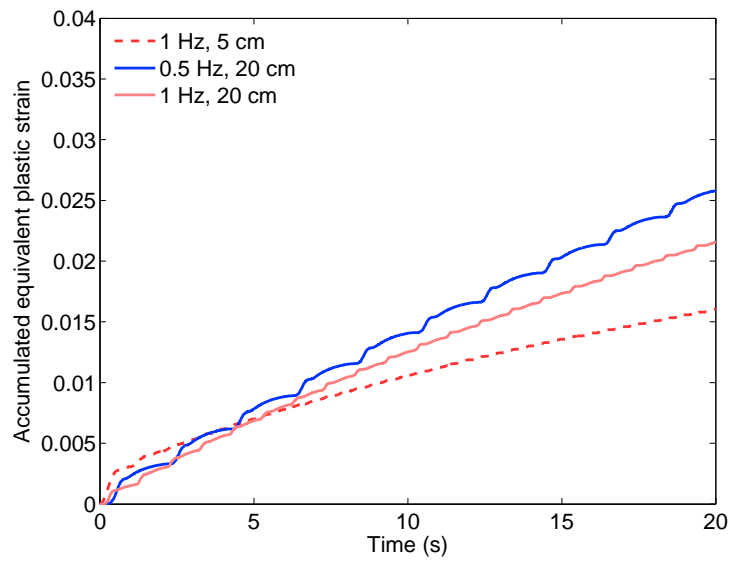

(b) Peak heat flux density: $20 \mathrm{MW} / \mathrm{m}^{2}$

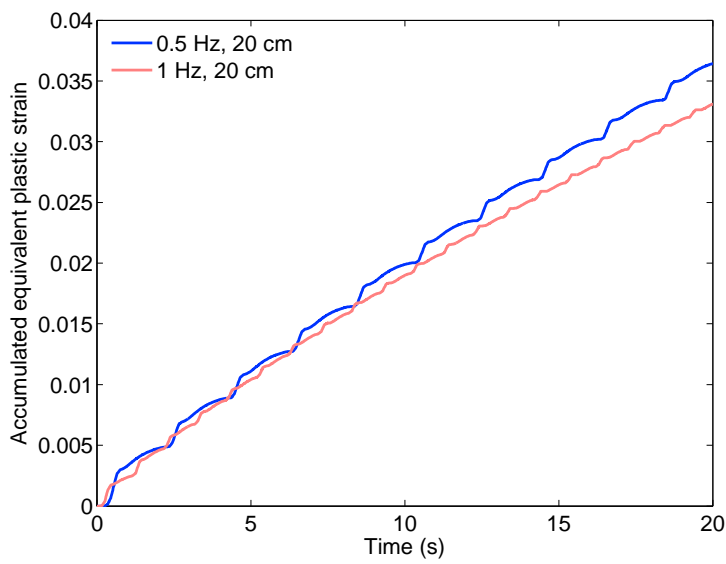

(c) Peak heat flux density: $30 \mathrm{MW} / \mathrm{m}^{2}$

Fig. 9. Accumulated equivalent plastic strain in the copper interlayer as a function of time for various combinations of loading parameters. 
Table 5. Predicted equivalent plastic strain range (\%) / fatigue lifetime ${ }^{a}$ in the copper interlayer.

\begin{tabular}{|c|c|c|c|c|}
\hline Peak heat flux density $\left(\mathrm{MW} / \mathrm{m}^{2}\right)$ & 10 & \multicolumn{3}{|c|}{15} \\
\hline Sweeping frequency $(\mathrm{Hz})$ & 1 & 0.5 & 1 & 4 \\
\hline Sweeping amplitude $(\mathrm{cm})$ & & & & \\
\hline 5 & & $0.064 / 119950$ & $0.021 / 852700$ & \\
\hline 20 & $0.018 / 1133500$ & $0.082 / 76430$ & $0.029 / 482960$ & $0.0009 / 1.99 \times 10^{8}$ \\
\hline Peak heat flux density $\left(\mathrm{MW} / \mathrm{m}^{2}\right)$ & 20 & & & 30 \\
\hline Sweeping frequency $(\mathrm{Hz})$ & 0.5 & 1 & 0.5 & 1 \\
\hline Sweeping amplitude (cm) & & & & \\
\hline 5 & - & $0.023 / 677900$ & - & - \\
\hline 20 & $0.112 / 44050$ & $0.040 / 271090$ & $0.159 / 24043$ & $0.064 / 118300$ \\
\hline
\end{tabular}

${ }^{a}$ Fatigue lifetime (allowed number of load cycles) was estimated from the reported fatigue data using plastic strain for unirradiated copper in the ITER Material Properties Handbook 24].

- critical heat flux is reached.

Table 6. Number of pulses (one pulse length of $7200 \mathrm{~s}$ ) before LCF failure in the copper interlayer.

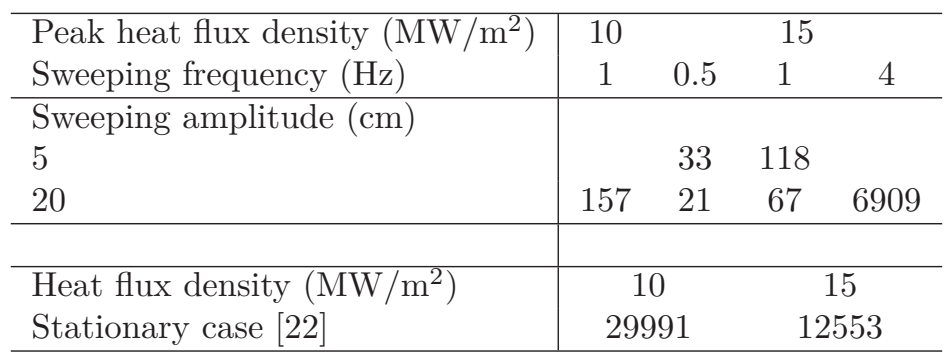

\section{Summary and conclusions}

In this paper, the results of an extensive computational study was reported which was carried out to assess the basic feasibility of the divertor heat flux sweeping technique in terms of the thermal and structural performance of a water-cooled tungsten mono-block target. Parametric finite element simulations demonstrated a significant thermal benefit of sweeping to reduce the peak temperature on the target, while the benefit in terms of structure-mechanical performance is shown only for certain loading scenarios. The sweeping amplitude and frequency turned out to have a considerable impact on the thermal efficiency of sweeping operation. The major predictions are summarized as follows:

1. The peak temperature decreases, when the sweeping amplitude or the sweeping frequency increases. The maximum heat flux to the coolant is significantly reduced by sweeping as well.

2. With an optimal combination of sweeping amplitude and frequency, even the extreme heat flux load of $30 \mathrm{MW} / \mathrm{m}^{2}$ could be accommodated without exceeding critical heat flux or armor melting point.

3. There is no general single trend between sweeping frequency (or amplitude) and the low cycle fatigue behavior. The impact depends on sweeping frequency and amplitude under consideration. 
4. For the parameters studied in this work, the increase of sweeping frequency (from 0.5 to $1 \mathrm{~Hz}$ ) or decrease of sweeping amplitude (from 20 to $5 \mathrm{~cm}$ ) has a beneficial effect on fatigue lifetime of the interlayer.

5. Sweeping offers advantages in terms of fatigue lifetime of interlayer as an emergency control action in case of a sudden increase of the thermal load on the divertor target.

6. Sweeping seems to be suitable as a steady state control scheme during normal operation if the sweeping frequency is high enough.

\section{Acknowledgement}

The authors are grateful to Dr. Fabio Crescenzi at ENEA for his providing us the data of heat transfer coefficient and critical heat flux. This work has been carried out within the framework of the EUROfusion Consortium and has received funding from the Euratom research and training programme 2014-2018 under grant agreement No 633053. The views and opinions expressed herein do not necessarily reflect those of the European Commission.

\section{References}

[1] M. Merola, D. Loesser, A. Martin, P. Chappuis, R. Mitteau, V. Komarov, R. Pitts, S. Gicquel, V. Barabash, L. Giancarli, J. Palmer, M. Nakahira, A. Loarte, D. Campbell, R. Eaton, A. Kukushkin, M. Sugihara, F. Zhang, C. Kim, R. Raffray, L. Ferrand, D. Yao, S. Sadakov, A. Furmanek, V. Rozov, T. Hirai, F. Escourbiac, T. Jokinen, B. Calcagno, S. Mori, ITER plasma-facing components, Fusion Engineering and Design 85 (2010) 2312-2322.

[2] A. Raffray, R. Nygren, D. Whyte, S. Abdel-Khalik, R. Doerner, F. Escourbiac, T. Evans, R. Goldston, D. Hoelzer, S. Konishi, P. Lorenzetto, M. Merola, R. Neu, P. Norajitra, R. Pitts, M. Rieth, M. Roedig, T. Rognlien, S. Suzuki, M. Tillack, C. Wong, High heat flux components - readiness to proceed from near term fusion systems to power plants, Fusion Engineering and Design 85 (2010) 93-108.

[3] G. Pintsuk, I. Bobin-Vastra, S. Constans, P. Gavila, M. Rödig, B. Riccardi, Qualification and post-mortem characterization of tungsten mock-ups exposed to cyclic high heat flux loading, Fusion Engineering and Design 88 (2013) 1858 - 1861.

[4] G. Pintsuk, M. Bednarek, P. Gavila, S. Gerzoskovitz, J. Linke, P. Lorenzetto, B. Riccardi, F. Escourbiac, Characterization of ITER tungsten qualification mock-ups exposed to high cyclic thermal loads, Fusion Engineering and Desigr doi:http://dx.doi.org/10.1016/j.fusengdes.2015.01.037

[5] J. H. You, A review on two previous divertor target concepts for DEMO: Mutual impact between structural design requirements and materials performance, Nuclear Fusion 55 (2015) 113026.

[6] E. Bertolini, Impact of JET experimental results and engineering development on the definition of the ITER design concept, Fusion Engineering and Design 27 (1995) 27 - 38.

[7] R. Albanese, G. Ambrosino, M. Ariola, A. Cenedese, F. Crisanti, G. D. Tommasi, M. Mattei, F. Piccolo, A. Pironti, F. Sartori, F. Villone, Design, implementation and test of the XSC extreme shape controller in JET, Fusion Engineering and Design 74 (2005) $627-632$. 
[8] G. Ambrosino, M. Ariola, G. De Tommasi, A. Pironti, F. Sartori, E. Joffrin, F. Villone, Plasma strike-point sweeping on JET tokamak with the eXtreme shape controller, Plasma Science, IEEE Transactions on 36 (2008) 834-840.

[9] R. Koenig, P. Grigull, K. McCormick, Y. Feng, J. Kisslinger, A. Komori, S. Masuzaki, K. Matsuoka, T. Obiki, N. Ohyabu, H. Renner, F. Sardei, F. Wagner, A. Werner, The divertor program in stellarators, Plasma Physics and Controlled Fusion 44 (2002) 2365.

[10] H. Renner, J. Boscary, H. Greuner, H. Grote, F. W. Hoffmann, J. Kisslinger, E. Strumberger, B. Mendelevitch, Divertor concept for the W7-X stellarator and mode of operation, Plasma Physics and Controlled Fusion 44 (2002) 1005.

[11] F. Maviglia, G. Federici, G. Strohmayer, R. Wenninger, C. Bachmann, R. Albanese, R. Ambrosino, M. Li, V. Loschiavo, J. You, L. Zani., Limitations of Transient Power Loads on DEMO and Analysis of Mitigation Techniques, 12th International Symposium on Fusion Nuclear Technology, Jeju, Korea, 2015 (accepted).

[12] T. Eich, A. Leonard, R. Pitts, W. Fundamenski, R. Goldston, T. Gray, A. Herrmann, A. Kirk, A. Kallenbach, O. Kardaun, A. Kukushkin, B. LaBombard, R. Maingi, M. Makowski, A. Scarabosio, B. Sieglin, J. Terry, A. Thornton, A. U. Team, J. E. Contributors, Scaling of the tokamak near the scrape-off layer H-mode power width and implications for ITER, Nuclear Fusion 53 (2013) 093031.

[13] F. Crescenzi, A. Moriani, S. Roccella, E. Visca, M. Richou, Water-cooled divertor target design study CuCrZr/W monoblock concept, EFDA report: WP13-DAS02-T02-D02 (2013).

[14] J. Lemaitre, J.-L. Chaboche, Mechanics of Solid Materials, 1st Edition, Cambridge University Press, 1994.

[15] P. J. Armstrong, C. O. Frederick, A mathematical representation of the multiaxial Bauschinger effect, G.E.G.B. Report $\mathrm{RD} / \mathrm{B} / \mathrm{N}(1966) 731$.

[16] J. Chaboche, Constitutive equations for cyclic plasticity and cyclic viscoplasticity, International Journal of Plasticity 5 (1989) 247-302.

[17] ITER structural design criteria for in-vessel components (SDC-IC) appendix A:Materials design limit data, ITER, (2001).

[18] J.-H. You, M. Miskiewicz, Material parameters of copper and CuCrZr alloy for cyclic plasticity at elevated temperatures, Journal of Nuclear Materials 373 (2008) 269-274.

[19] E. N. Sieder, G. E. Tate, Heat transfer and pressure drop of liquids in tubes, Industrial \& Engineering Chemistry 28 (1936) 1429-1435.

[20] J. Thom, W. Walker, T. Fallon, G. Reising, Boiling in sub-cooled water during flow up heated tubes or annuli., Proceedings of the Institution of Mechanical Engineers (London), 180: Pt 3C, 226-46(1965-66).

[21] M. Li, E. Werner, J.-H. You, Fracture mechanical analysis of tungsten armor failure of a water-cooled divertor target, Fusion Engineering and Design 89 (2014) 2716-2725.

[22] M. Li, E. Werner, J.-H. You, Low cycle fatigue behavior of ITER-like divertor target under DEMO-relevant operation conditions, Fusion Engineering and Design 90 (2015) 88-96.

[23] Abaqus analysis user's manual 6.12., Dassault Systémes Simulia Corp., Providence, RI, USA, 2012.

[24] ITER Material Properties Handbook, ITER Document No.G74 MA 16, 2005.

[25] G. Giruzzi, J. Artaud, M. Baruzzo, T. Bolzonella, E. Fable, L. Garzotti, I. Ivanova-Stanik, R. Kemp, D. King, M. Schneider, R. Stankiewicz, W. Stępniewski, P. Vincenzi, D. Ward, R. Zagórski, Modelling of pulsed and steady-state DEMO scenarios, Nuclear Fusion 55 (2015) 073002. 
Fig.1

Outer target heat power footprint

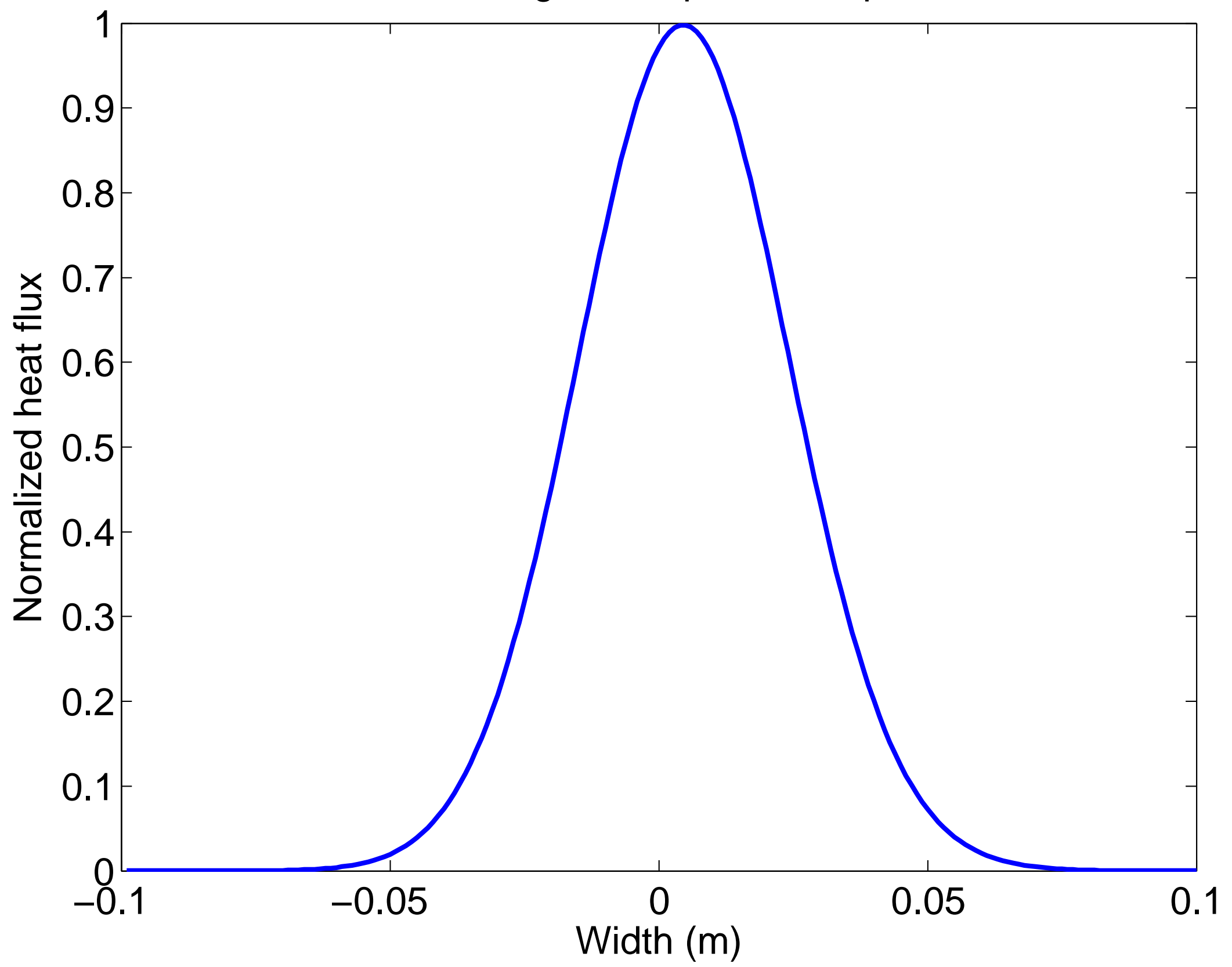


Fig.2

sweeping directions:

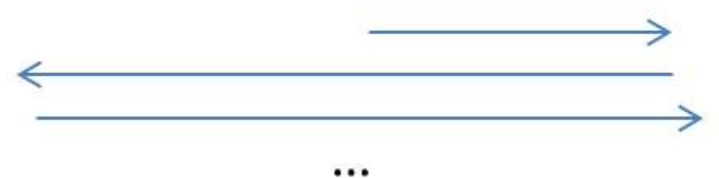

foot print of the heat flux power

sweeping amplitude, $a$
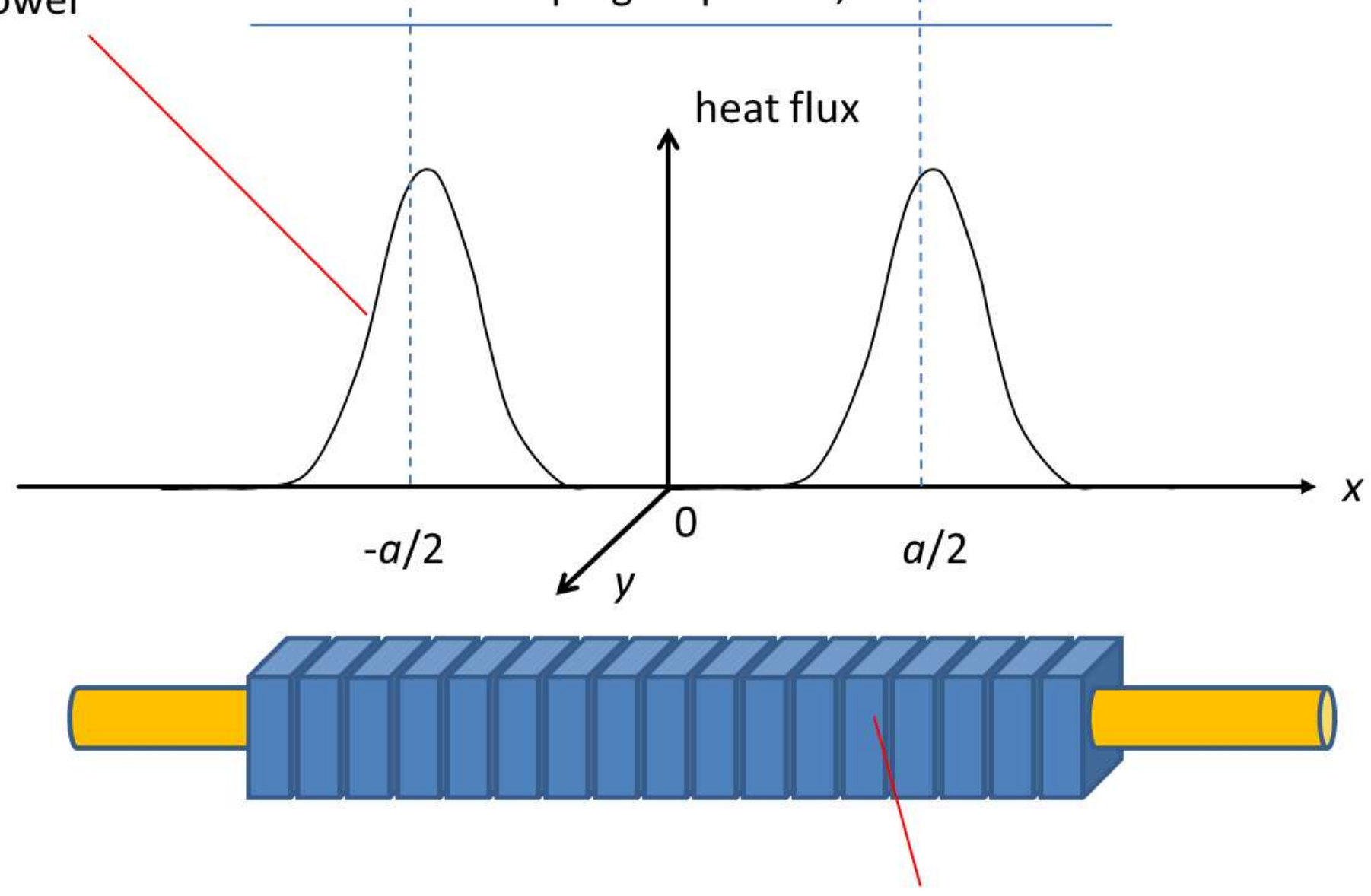

selected divertor 
Fig.4

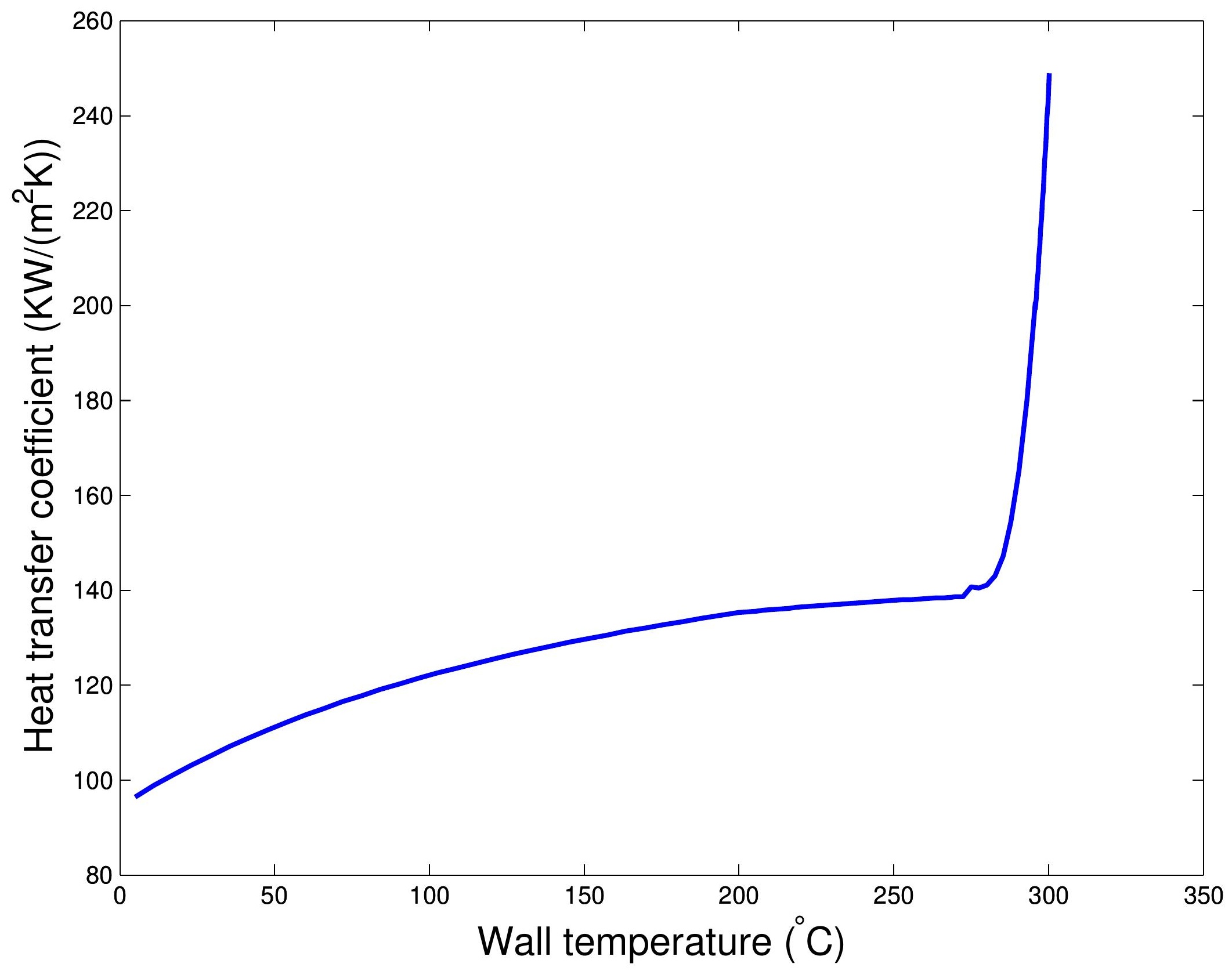


$\left({ }^{\circ} \mathrm{C}\right)$

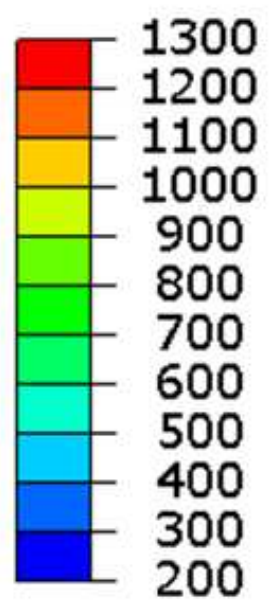

node 1

node 2

node 3
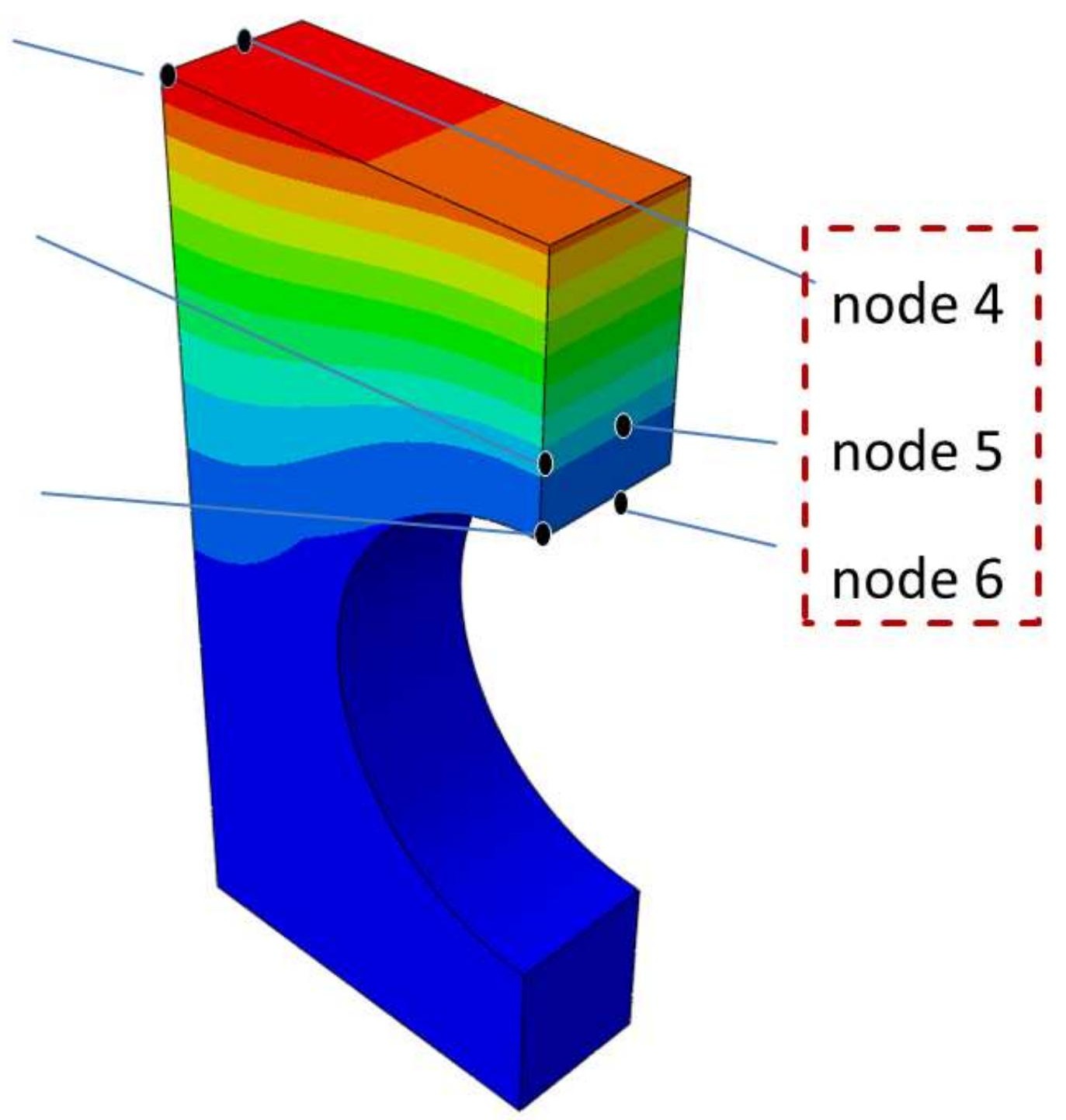
Fig.6

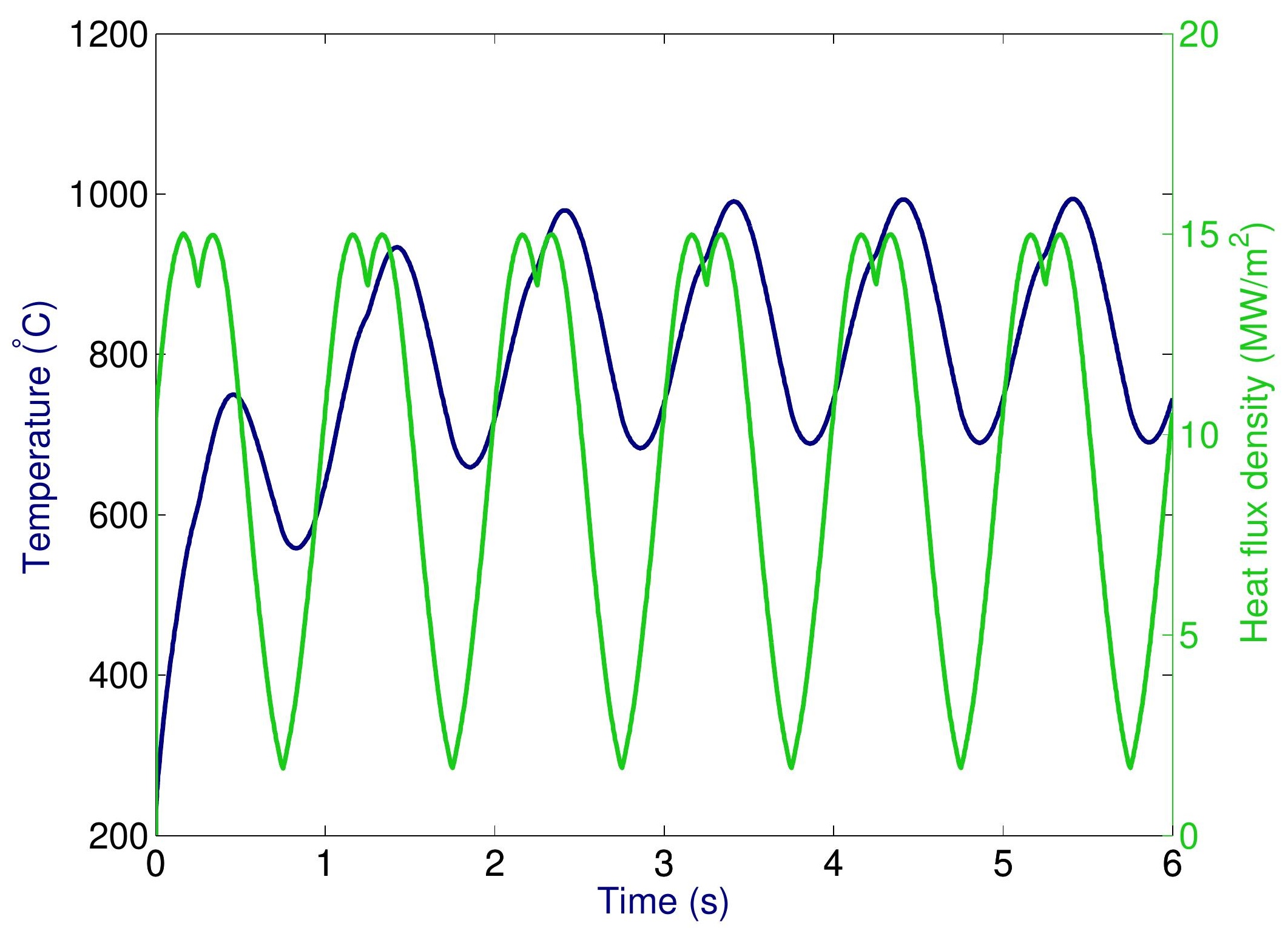


Fig.7 (b)

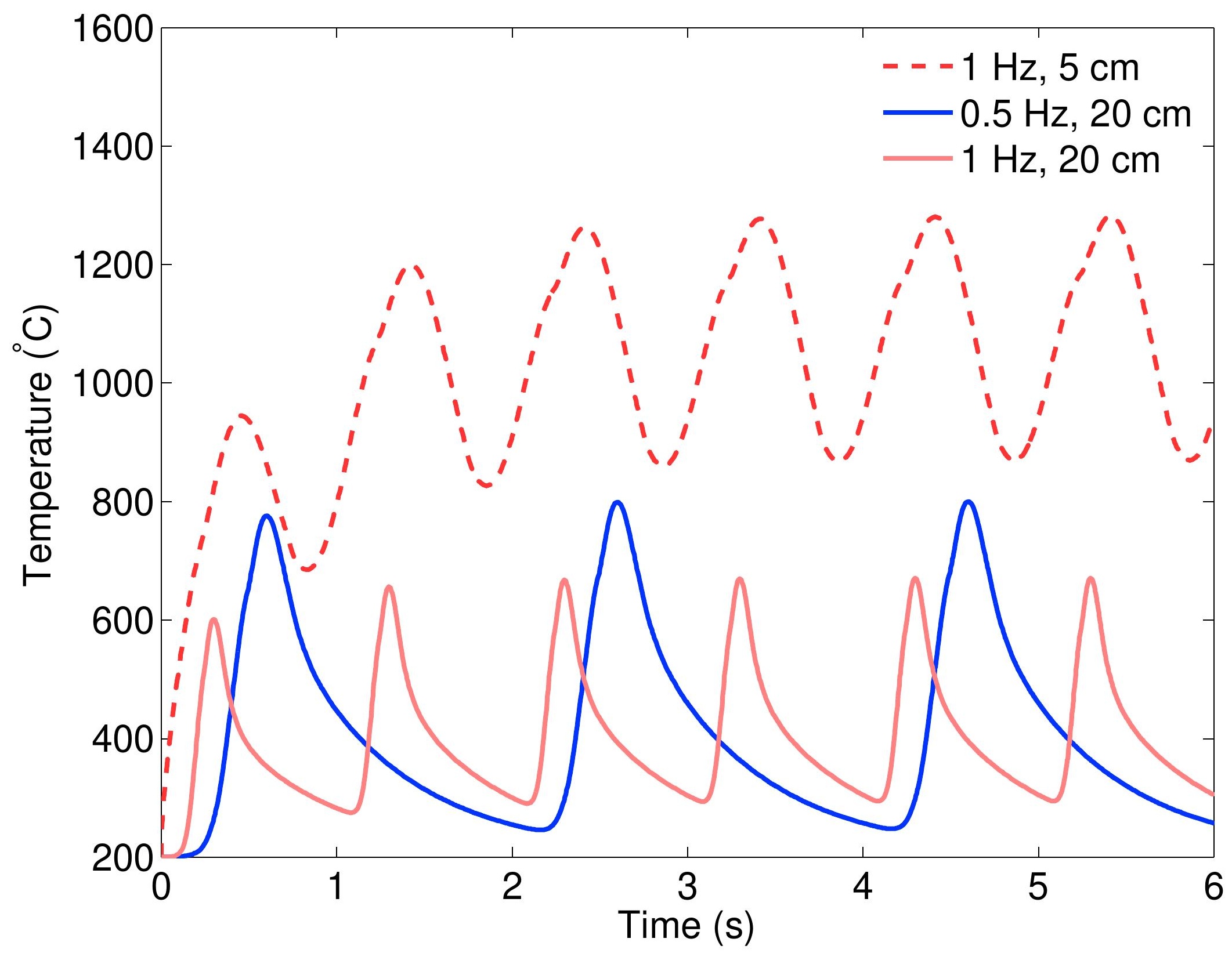


Fig.7 (c)

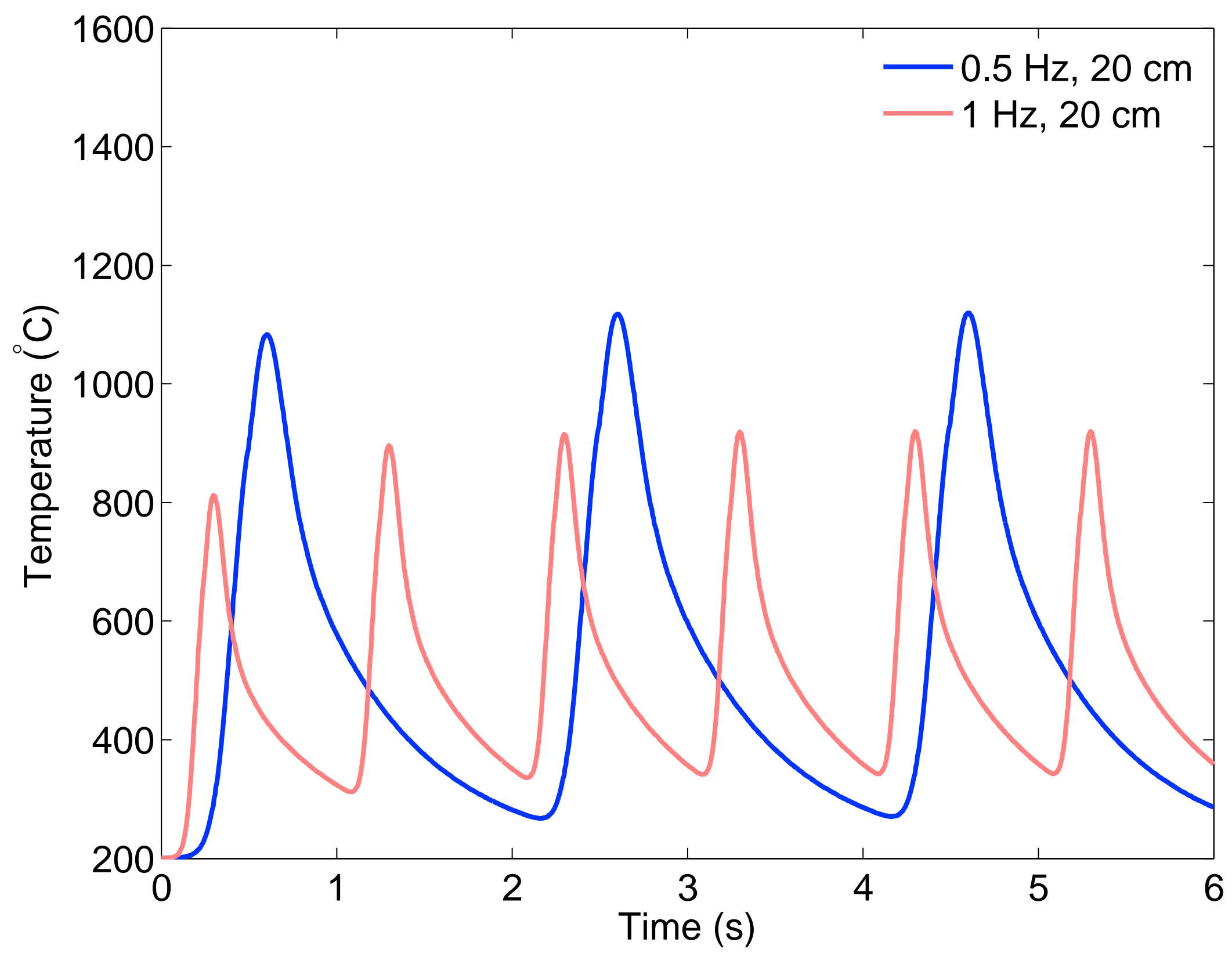


Fig.8 (a)

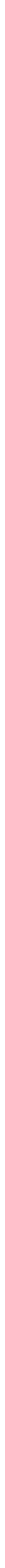

6 
Fig.8 (b)

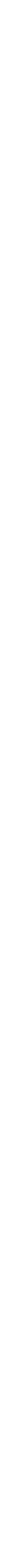


Fig.8 (c)

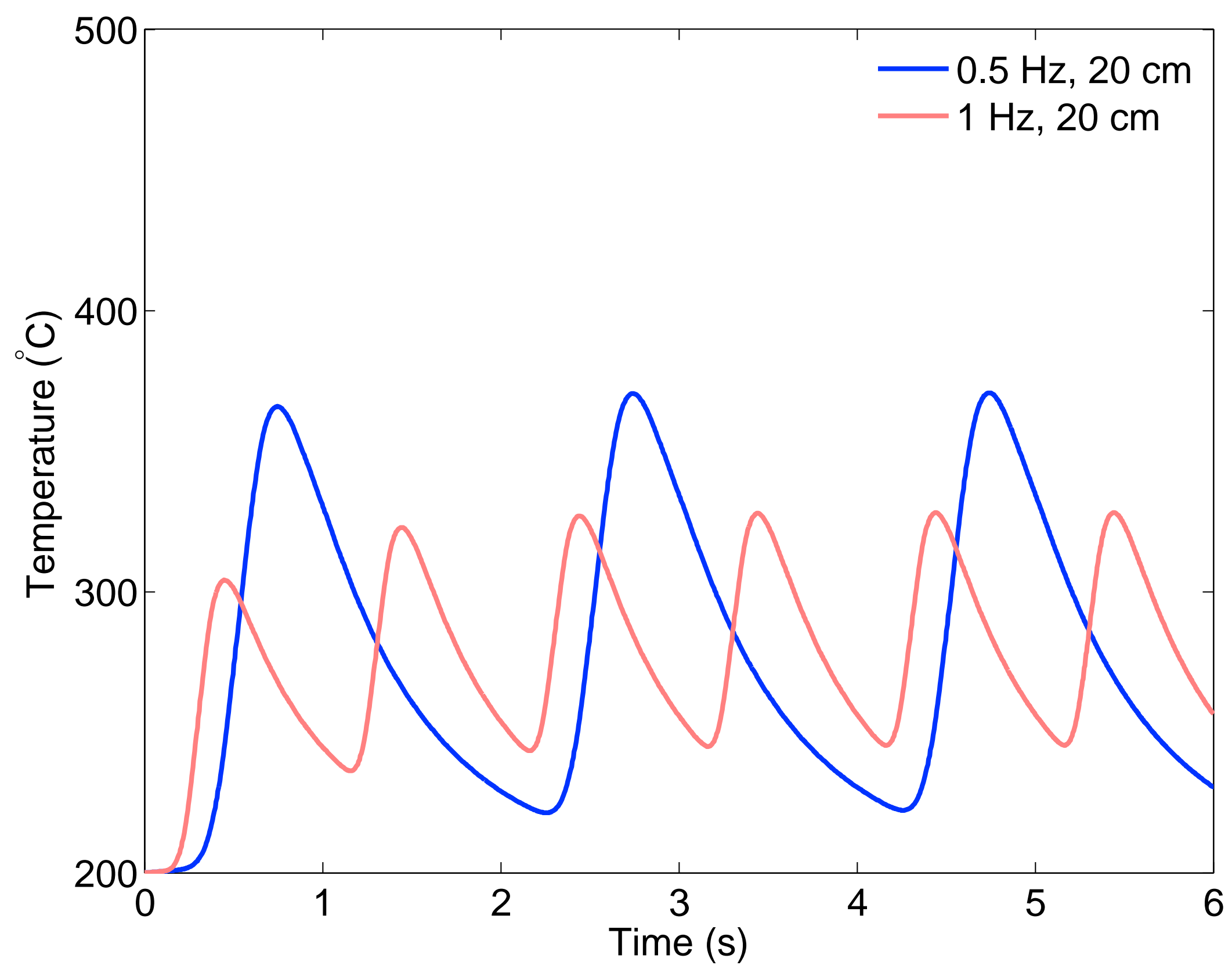


Fig.9 (a)

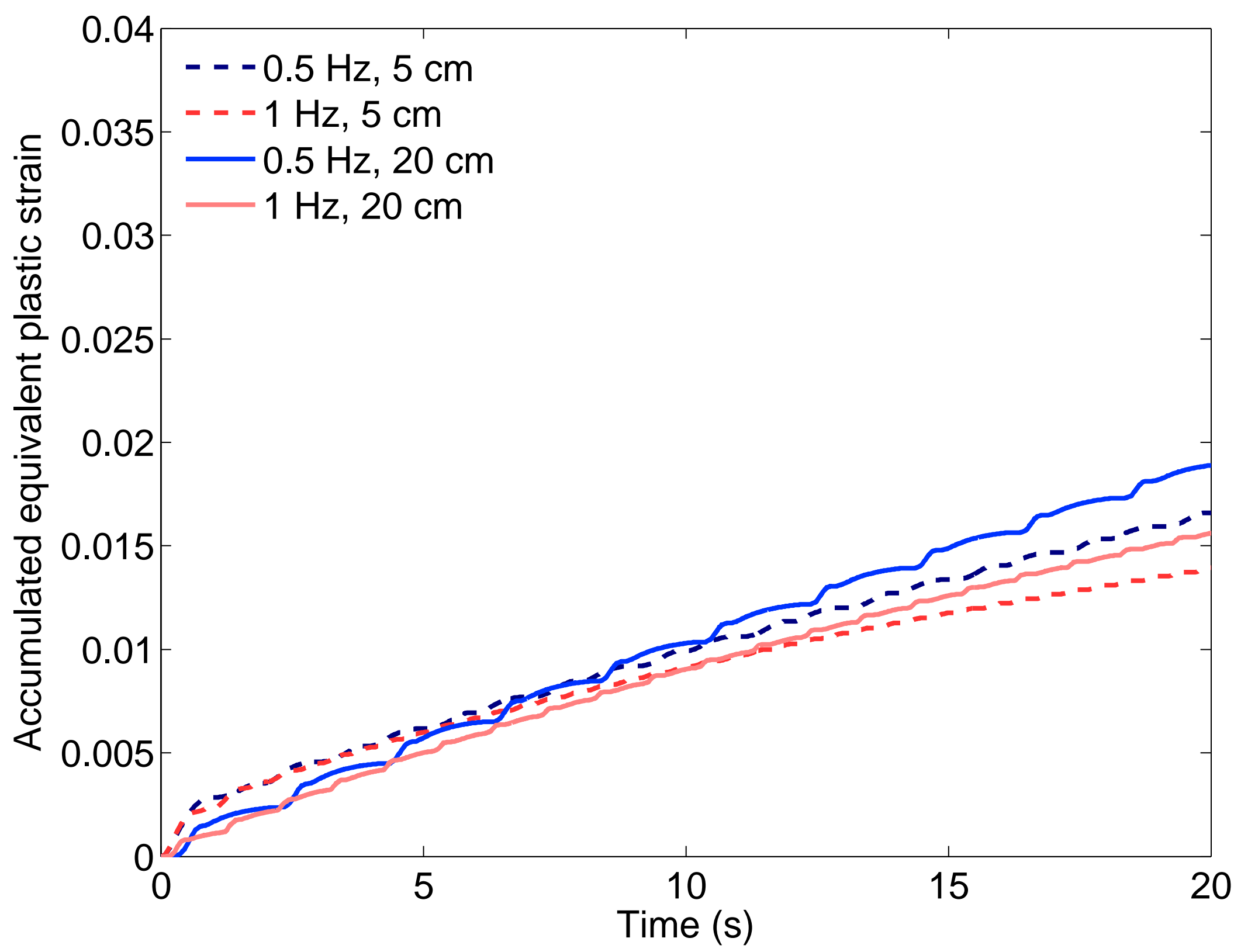


Fig.9 (c)

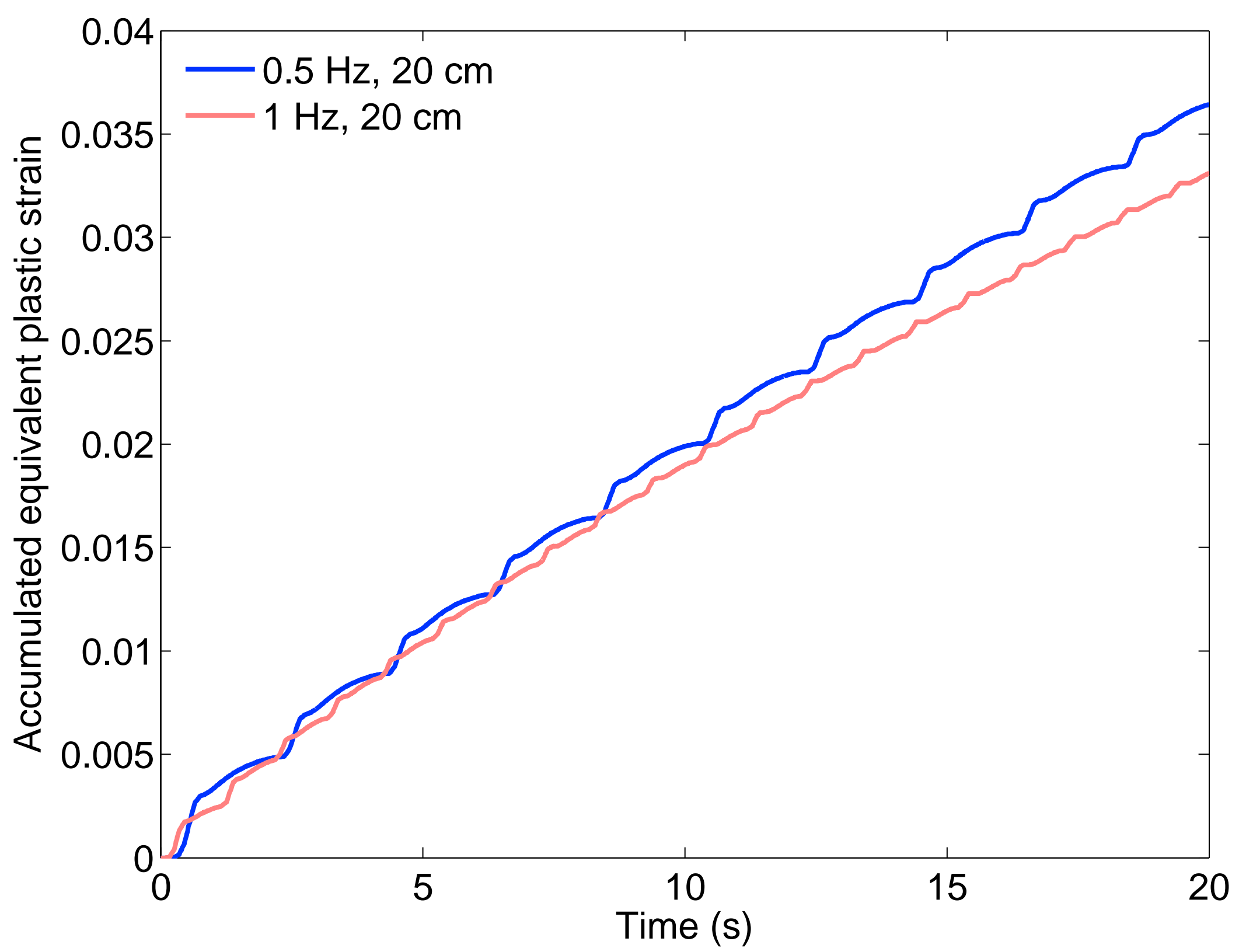


LaTeX Source Files
Click here to download LaTeX Source Files: Latex.zip

LaTeX Source Files
Click here to download LaTeX Source Files: Latex.zip Click here to download LaTeX Source Files: Latex.zip

$(2+2$

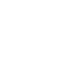

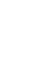

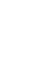

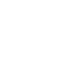
(1) (1) $\sqrt{3}$ (1)

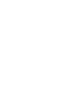
(1) (1) $\sqrt{2}$ (1) 更 (1) . 